\title{
Biodégradabilité de l'essence dans l'environnement : de l'évaluation globale au cas des hydrocarbures récalcitrants
}

\author{
F. Solano-Serena ${ }^{1 *}$, R. Marchal ${ }^{1}$ et J.P. Vandecasteele ${ }^{1}$ \\ 1 Institut français du pétrole, département de Microbiologie, \\ 1 et 4, avenue de Bois-Préau, 92852 Rueil-Malmaison Cedex - France \\ e-mail : leglise@ensil.unilim.fr - remy.marchal@ifp.fr - i-paul.vandecasteele@ifp.fr \\ *Le travail expérimental présenté a été réalisé par Floriane Solano-Serena au cours de sa thèse, \\ soutenue à l'UTC (Université de technologie de Compiègne). \\ Floriane Solano-Serena a obtenu le Prix de Thèse 2000 attribué par le Conseil scientifique de l'IFP. \\ *The experimental work presented was carried out by Floriane Solano-Serena during her PhD Thesis \\ of UTC (Université de technologie de Compiègne). \\ Floriane Solano-Serena has obtained the Thesis Price for the year 2000 awarded by the Scientific Committee of IFP.
}

\begin{abstract}
Résumé - Les produits pétroliers, du fait de leur utilisation massive, constituent des polluants importants des sols et des aquifères. Le devenir de ces polluants rejetés dans l'environnement est principalement gouverné par les processus de biodégradation. L'existence de ces phénomènes dépend de la biodégradabilité intrinsèque du polluant mais aussi de la présence de microflores dégradatrices compétentes dans les sols et les eaux souterraines.

Au cours de ce travail, nous avons développé une méthodologie permettant d'évaluer la biodégradabilité de l'essence en conditions aérobies. Elle consiste à mesurer, par chromatographie en phase gazeuse, après incubation dans des conditions optimales, la consommation de chacun des hydrocarbures présents dans différentes fractions de l'essence (essence réelle, mélanges modèles).

Les résultats indiquent que la biodégradabilité de l'essence est quasi totale (94\%). Les microflores de l'environnement ont des capacités élevées (85\% et plus de dégradation). Les performances des microflores de sols non pollués sont cependant limitées pour la dégradation des triméthylalcanes, comme le 2,2,4-triméthylpentane (isooctane) ou le 2,3,4-triméthylpentane, et des cycloalcanes. Les microflores provenant de sols pollués ont des capacités de dégradation plus larges puisque la dégradation est totale pour la moitié des échantillons étudiés. Le cyclohexane est toujours dégradé par mutualisme et/ou cométabolisme. Les triméthylalcanes avec un atome de carbone quaternaire, comme l'isooctane, et/ou des groupements méthyles sur des atomes de carbone consécutifs sont dégradés par cométabolisme mais peuvent aussi servir de substrat de croissance à des souches spécialisées. Une souche, Mycobacterium austroafricanum (IFP 2173), capable de croissance sur isooctane, a été isolée à partir d'un échantillon pollué par essence. Cette souche a la capacité de cométaboliser certains hydrocarbures (cyclo- et iso-alcanes, aromatiques) et en particulier le cyclohexane. M. austroafricanum IFP 2173 peut aussi utiliser pour sa croissance un large spectre d'hydrocarbures ( $n$ - et iso-alcanes, aromatiques).

Mots-clés : biodégradation, essence, hydrocarbures, microflores de sols, pollution des sols, capacité de dégradation, isooctane.
\end{abstract}




\begin{abstract}
Biodegradation of Gasoline in the Environment: From Overall Assessment to the Case of Recalcitrant Hydrocarbons - Because of their massive utilisation, hydrocarbons are major pollutants of soils and aquifers. Biodegradation is a key aspect of the fate of pollutants in the environment. Such knowledge concerns in particular the intrinsic biodegradability of the products and the distribution in the environment of competent degradative microflorae.

In this study, a methodology has been developed to assess the aerobic biodegradability of gasoline. It is based on the direct gas chromatographic analysis of all hydrocarbons, after incubation in optimal conditions, of gasoline fractions and of model mixtures.

The results first demonstrated the quasi-total biodegradability of gasoline (94\%). Concerning the distribution in the environment of degradative capacities, even microflorae from non-polluted sites exhibited a high performance (total degradation rate: at least $85 \%$ ) but were limited concerning the degradation of trimethylalkanes, such as 2,2,4-trimethylpentane (isooctane) and 2,3,4-trimethylpentane, and of cyclohexane. Samples of polluted sites exhibited more extensive degradative capacities with total degradation in half of the cases studied. Cyclohexane was always degraded by mutualism and/or cometabolism. Trimethylalkanes with quaternary carbons such as isooctane and/or alkyl groups on consecutive carbons were degraded by cometabolism but could also support growth of specialised strains. A strain of Mycobacterium austroafricanum (strain IFP 2173) growing on isooctane was isolated from a gasoline-polluted sample. This strain exhibited the capacity to cometabolise various hydrocarbons (cyclic and branched alkanes, aromatics) and in particular cyclohexane. M. austroafricanum IFP 2173 was also able to use a large spectrum of hydrocarbons (n- and iso-alkanes, aromatics) as sole carbon and energy source.

Keywords: biodegradation, gasoline, hydrocarbons, soil microflora, soil pollution, degradative capacity, isooctane.
\end{abstract}

\section{INTRODUCTION}

Les produits pétroliers et leurs dérivés constituent les principaux polluants organiques des sols et des eaux souterraines. Cette situation est la conséquence d'un emploi massif (105 millions de tonnes pour la France en 1999) qui s'accompagne du rejet des produits de combustion et des produits eux-mêmes par les fuites des réservoirs de stockage. Le devenir de ces polluants, une fois rejetés dans l'environnement, dépend alors principalement de l'importance des processus de biodégradation qui peuvent exister dans les sols et les nappes aquifères.

La connaissance de la biodégradabilité des produits pétroliers (essence, kérosène, gazole, etc.) représente un enjeu évident. En effet, en cas de pollution accidentelle, il convient d'être en mesure d'apprécier les capacités d'auto-épuration du milieu naturel (atténuation naturelle) pour établir une stratégie et mettre en place, si nécessaire, les opérations de réhabilitation. Par ailleurs, et dans un cadre plus général, on se doit également d'être en mesure de juger de l'acceptabilité vis-à-vis de l'environnement des produits présents sur le marché. Cet aspect, qui est encore actuellement mal perçu, est pourtant primordial. Dans le cas idéal, la réglementation ne devrait autoriser que les produits qui, dans leurs conditions d'utilisation, ne conduisent pas à des situations inacceptables au plan environnemental (pollution de captages d'eau par exemple). À cet égard, le cas des éthers-carburants est riche d'enseignements. Le méthyl $t$-butyl éther (MTBE) a été introduit de façon massive dans les essences dans les années 80 pour maintenir un indice d'octane acceptable dans les formulations sans plomb. L'absence d'études préalables n'avait pas permis d'apprécier la récalcitrance de ce composé à la biodégradation. Les cas de pollutions multiples ont finalement abouti, en 1999, à la décision de bannir purement et simplement le MTBE en Californie, le plus gros État utilisateur de ce produit.

L'évaluation de la biodégradabilité d'un polluant dans l'environnement fait appel à trois types d'information :

- les premières concernent la biodégradabilité intrinsèque, c'est-à-dire l'existence et les modalités de processus de biodégradation, en conditions optimales et avec une microflore appropriée. C'est à ce niveau que se justifient tous les travaux fondamentaux de microbiologie pour l'élucidation des mécanismes impliqués aux plans physiologique et biochimique ;

- les deuxièmes concernent la distribution des capacités de dégradation dans différents milieux de l'environnement. Ainsi, selon le polluant considéré, la capacité de dégradation peut être largement répandue ou parfois restreinte à des niches particulières ;

- les troisièmes sont relatives aux conditions locales existant sur un site précis en cas de pollution : paramètres physicochimiques ( $\mathrm{pH}$, température, humidité, salinité, etc.), présence d'accepteurs d'électrons $\left(\mathrm{O}_{2}\right.$, nitrates, sulfates, fer ferrique, etc.) et d'éléments nutritionnels (azote et phosphore notamment) indispensables au métabolisme des microorganismes. Des facteurs d'ordre hydrogéologique pertinents doivent également être considérés car ils conditionnent eux aussi, pour une large part, les capacités d'atténuation naturelle en un site donné. 
Le travail présenté a pour objectif de fournir une information détaillée relative à la biodégradabilité intrinsèque de l'essence et à la distribution dans l'environnement des capacités microbiologiques de dégradation. L'acceptabilité de l'essence par l'environnement est une question actuelle en raison de l'évolution récente et à venir des formulations des carburants, conséquence des nouvelles normes sur la qualité de l'air. L'évaluation de la biodégradabilité nécessite des connaissances sur la microbiologie des hydrocarbures. Dans ce domaine, il est surprenant de constater que la biodégradabilité intrinsèque de l'essence n'est que très mal décrite dans la littérature. Deux points méritent ainsi d'être relevés. Tout d'abord, l'essence est un mélange complexe d'environ 200 hydrocarbures, tous identifiables. Les études très détaillées menées depuis les années 60 n'ont concerné que certains hydrocarbures, certes parfois très importants, comme les hydrocarbures monoaromatiques, benzène, toluène, éthylbenzène, xylène (BTEX), mais qui ne représentent numériquement qu'une minorité des constituants présents. L'autre point est que la dégradation de tels mélanges ne peut être assimilée à la somme des dégradations des composés individuels. Des interactions importantes, telles que le cométabolisme (dégradation partielle d'un composé non utilisé pour la croissance), peuvent exister dans un mélange et peuvent modifier très sensiblement ses caractéristiques de biodégradabilité. Les travaux sur le cométabolisme des différentes classes d'hydrocarbures (cyclohexane, BTEX, hydrocarbures polyaromatiques) restent limités à certains cas particuliers.

La méthodologie utilisée pour évaluer la biodégradabilité consiste à réaliser des incubations en milieu liquide, en fioles fermées hermétiquement. Des microorganismes (population mixte ou souche pure) et des hydrocarbures sont mis en $œ u v r e$ dans un milieu nutritif ne contenant que des sels minéraux et des vitamines. Les hydrocarbures constituent donc la seule et unique source de carbone utilisable par les microorganismes. Le substrat de référence étudié est une essence sans plomb 98, dépourvue de composés oxygénés. Pour des raisons analytiques, cette essence a été distillée à $76{ }^{\circ} \mathrm{C}$. Cette distillation a fourni une fraction légère (fraction de tête), contenant des composés ayant de 4 à 6 atomes de carbone, et une fraction plus lourde (essence étêtée), contenant majoritairement des composés ayant de 6 à 10 atomes de carbone. Ces deux fractions ont été utilisées séparément au cours des tests d'évaluation de la biodégradabilité de l'essence. Par ailleurs, deux mélanges synthétiques, appelés mélanges modèles, ont été préparés avec les hydrocarbures identifiés comme étant majoritaires dans chacune des deux fractions. Les hydrocarbures présents dans les mélanges modèles ont aussi été fournis individuellement comme sources de carbone. D'autres composés individuels, présents dans l'essence (hydrocarbures ou éthers-carburants) ou dans d'autres produits pétroliers (hexadécane, pristane), ont aussi été utilisés pour tester les capacités de dégradation de souches pures (fig. 1). La concentration d'hydrocarbures dans les tests de biodégradation, sauf lorsque cela est précisé, est de l'ordre de $400 \mathrm{mg}$ par litre de culture.

La présentation des résultats s'articule autour de trois grandes parties :

- dans un premier temps, les travaux sur l'évaluation de la biodégradabilité intrinsèque d'une essence réelle, complète, en prenant en compte tous les hydrocarbures identifiables et quantifiables, sont présentés. L'évaluation de la biodégradabilité a été réalisée en utilisant une microflore de boues activées de station d'épuration urbaine comme microflore de référence ;

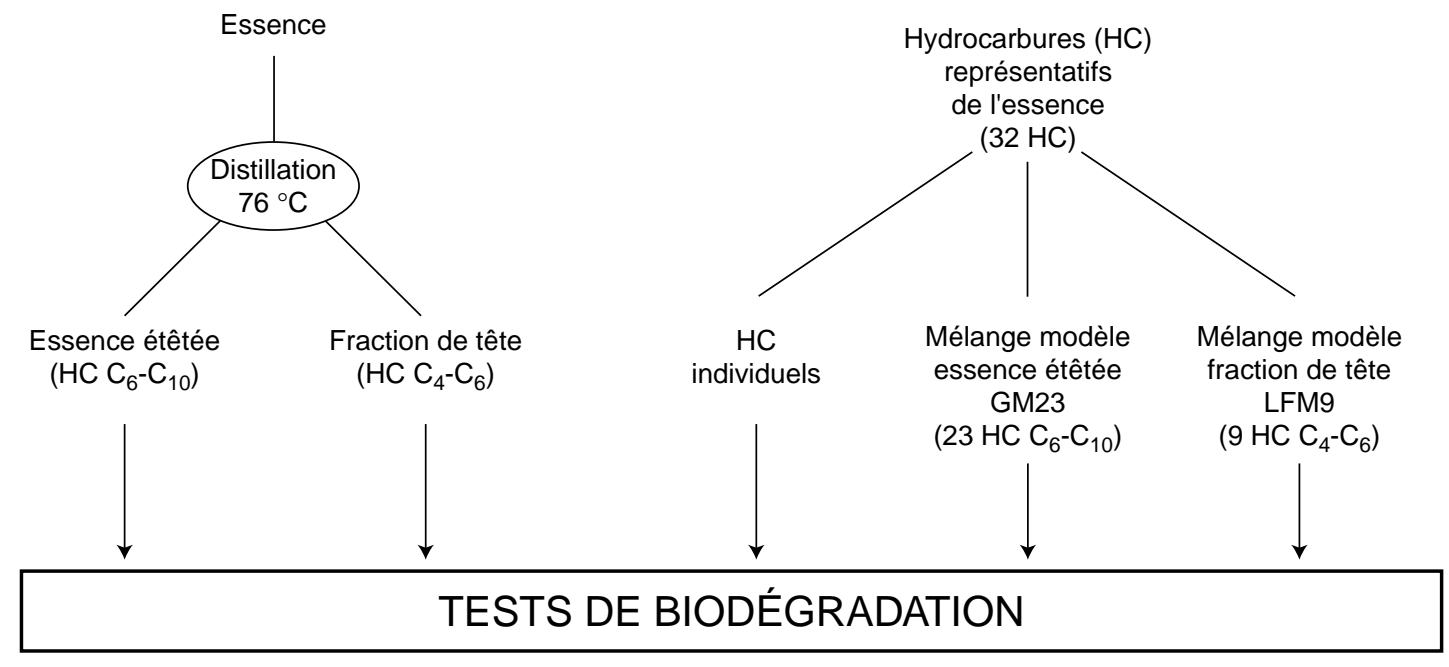

Figure 1

Hydrocarbures utilisés pour les tests de biodégradation.

Hydrocarbons used for degradation tests. 
- dans une deuxième partie, en s'appuyant sur les résultats précédents, la distribution des capacités de dégradation dans des environnements pollués ou non pollués est examinée. Cette démarche a été rendue possible par le développement et la validation d'une méthodologie utilisant un mélange synthétique d'hydrocarbures, représentatif de l'essence, mais moins lourd à mettre en œuvre ;

- les résultats présentés dans les deux premières parties ont clairement mis en évidence l'existence de composés plus résistants à la biodégradation ou pour lesquels les microflores de l'environnement sont déficientes. Par conséquent, dans la troisième partie, nous nous sommes attachés à développer les connaissances sur la biodégradabilité de ces hydrocarbures et en particulier celle des isoalcanes très ramifiés comme l'isooctane (2,2,4-triméthylpentane). L'isooctane occupe une place particulière dans la composition de l'essence-carburant, notamment à cause de la valeur élevée de son indice d'octane. Les connaissances microbiologiques à son sujet sont lacunaires. Pour ces raisons, les capacités de dégradation d'une souche, sélectionnée pour sa capacité à utiliser l'isooctane comme seule source de carbone, sont présentées plus en détail.

\section{BIODÉGRADABILITÉ DE L'ESSENCE}

\subsection{Présentation}

La mise au point des méthodologies permettant de mieux appréhender la biodégradabilité intrinsèque de l'essence est primordiale (Logan et Rittmann, 1998). Comme nous l'avons déjà évoqué, les éléments concernant la biodégradation de l'essence n'étaient disponibles que pour certains composés. La biodégradabilité des principaux composés, comme le benzène (Paje et al., 1997), le toluène (Leahy et Olsen, 1997), l'éthylbenzène et les isomères du xylène (Di Lecce et al., 1997), par des souches pures et des microflores complexes (Mallakin et Ward, 1996 ; Tsao et al., 1998) était clairement établie. En revanche, peu d'informations étaient disponibles à propos de la dégradation des autres composés de l'essence, excepté pour les $n$-alcanes (Vestal 1984 ; Watkinson et Morgan, 1990), quelques alcanes ramifiés (Schaeffer et al., 1979 ; Thijsse et Van der Linden, 1961, 1963) et quelques dérivés benzéniques polysubstitués (Lang, 1996 ; Rozkov et al., 1998). Les travaux concernant la biodégradation de l'essence mentionnaient un taux global de dégradation important (Yerushalmi et Guiot, 1998 ; Zhou et Crawford, 1995), mais n'apportaient aucun élément quant au devenir de chacun des composés au sein du mélange essence (excepté pour les BTEX). C'est pour cette raison que nous avons voulu effectuer une évaluation détaillée (analyse des hydrocarbures individuels) en utilisant la méthodologie présentée dans le tableau 1.

\section{TABLEAU 1}

Méthodologie d'évaluation des capacités intrinsèques des microflores pour la dégradation de l'essence

Methodology used to evaluate the intrinsic capacities of microflorae for gasoline degradation

Tests de biodégradation de l'essence en réacteur agité (système fermé) en conditions optimales :

- présence d'accepteur d'électrons $\left(\mathrm{O}_{2}\right)$ et de nutriments en excès, substrat accessible et en quantité inférieure à la concentration toxique ;

- utilisation de mélanges pour permettre l'intervention du cométabolisme.

Suivi en cours de dégradation par dosage chromatographique du $\mathrm{CO}_{2}$ produit.

Détermination quantitative de la biodégradation : analyses initiale et finale de chacun des hydrocarbures du mélange par chromatographie.

Les tests consistent à déterminer en système fermé la biodégradation de chacun des hydrocarbures identifiables et analysables de l'essence. Ces tests ont été réalisés dans des conditions optimales en ce qui concerne les paramètres environnementaux : accessibilité du polluant, apport en nutriments, quantité d'oxygène disponible. Les hydrocarbures et le $\mathrm{CO}_{2}$ sont analysés par chromatographie en phase gazeuse (CPG), comme décrit par Solano-Serena et al. (1998), après incubation dans des fioles d'essai et des fioles témoins :

- essai : milieu nutritif + microorganismes + hydrocarbures ;

- témoin abiotique : milieu nutritif + microorganismes + hydrocarbures + inhibiteur d'activité microbiologique ;

- témoin de respiration endogène : milieu nutritif + microorganismes.

Le taux de dégradation est déterminé par le rapport entre le substrat consommé dans les essais et le substrat présent dans les témoins abiotiques. La quantité de substrat consommée est déterminée par différence entre ce qui est dosé dans les essais et dans les témoins abiotiques.

Le taux de minéralisation est le rapport du nombre total de moles de carbone dégradées en $\mathrm{CO}_{2}$ sur le nombre de moles de carbone du substrat consommées ou initialement introduites, selon les cas. Seule la production de $\mathrm{CO}_{2}$ à partir du substrat est prise en compte ; le nombre de moles de $\mathrm{CO}_{2}$ produites dans les fioles témoins de respiration endogène est déduit de la quantité de $\mathrm{CO}_{2}$ déterminée dans les essais.

Une microflore de référence, provenant d'une station d'épuration d'eaux usées urbaines (boues activées), choisie pour les larges capacités de dégradation reconnues à de telles microflores, a été utilisée pour obtenir une première approximation de la biodégradabilité intrinsèque. La composition de l'essence utilisée comme substrat de référence, une essence commerciale contenant plus de 200 hydrocarbures, est présentée dans le tableau 2. En fait, comme déjà mentionné, les essais ont été réalisés avec deux fractions distinctes obtenues par distillation à $76^{\circ} \mathrm{C}$ de l'essence commerciale (fig. 2). 
TABLEAU 2

Composition massique de l'essence sans plomb 98 utilisée comme référence

Composition of the unleaded gasoline used as reference

\begin{tabular}{l|c|c|c}
\hline $\begin{array}{c}\text { Familles } \\
\text { d'hydrocarbures }\end{array}$ & $\begin{array}{c}\text { Fraction de tête } \\
\left.\left(\mathrm{C}_{4}-\mathrm{C}_{6}\right)\right) \\
(\%)\end{array}$ & $\begin{array}{c}\text { Essence étêtée } \\
\left(\mathrm{C}_{6}-\mathrm{C}_{10}\right) \\
(\%)\end{array}$ & $\begin{array}{c}\text { Essence } \\
\text { totale } \\
(\%)\end{array}$ \\
\hline$n$-alcanes & $7,90^{*}$ & 1,36 & 9,26 \\
\hline $\begin{array}{l}\text { Méthyl- } \\
\text { et diméthyl-alcanes }\end{array}$ & 22,70 & 6,33 & 29,03 \\
\hline Triméthylalcanes & 0 & 5,72 & 5,72 \\
\hline Cycloalcanes & 0,61 & 1,15 & 1,76 \\
\hline BTEX & 0 & $35,70 * *$ & 35,70 \\
\hline $\begin{array}{l}\text { Autres mono- } \\
\text { et di-alkylbenzènes }\end{array}$ & 0 & 5,91 & 5,91 \\
\hline $\begin{array}{l}\text { Tri- } \\
\text { et tétra-alkylbenzènes }\end{array}$ & 0 & 5,70 & 5,70 \\
\hline Autres aromatiques & 0 & 2,22 & 2,22 \\
\hline Alcènes & 3,84 & 0,86 & 4,70 \\
\hline Essence totale & 35,05 & 64,95 & 100 \\
\hline
\end{tabular}

* Hexane inclus.

** Benzène inclus.

La fraction de tête représente $35 \%$ de l'essence totale (tableau 2). Les hydrocarbures de cette fraction sont analysés par CPG après échantillonnage de la phase gazeuse présente au-dessus du milieu de culture. Les hydrocarbures de la fraction la plus lourde sont par contre analysés par CPG après extraction au solvant (dichlorométhane). Deux méthodes d'analyse ont été nécessairement mises en œuvre. En effet, d'une part, l'extraction au solvant des hydrocarbures de la fraction de tête ne peut être réalisée car les rendements d'extraction ne sont pas satisfaisants. À titre d'exemple, ils sont respectivement de 50 et $80 \%$ pour le butane et le pentane. D'autre part, l'analyse par échantillonnage de l'espace de tête est satisfaisante pour la fraction légère. Pour la fraction plus lourde cette méthode permet d'obtenir un résultat global (Zhou et Crawford, 1995 ; Yerushalmi et Guiot, 1998), mais ne permet pas l'analyse précise de chaque hydrocarbure. Les constantes de Henry, corrélant les concentrations dans la phase gazeuse avec celles de la phase liquide, sont en effet très disparates (Yaws, 1992 ; Nirmalakhandan et al., 1997).

L'évaluation de la biodégradabilité des hydrocarbures de l'essence est tout d'abord présentée pour la fraction légère $\mathrm{C}_{4}-\mathrm{C}_{6}$ et ensuite pour la fraction plus lourde $\mathrm{C}_{6}-\mathrm{C}_{10}$.

\subsection{Biodégradabilité de la fraction de tête $\left(\mathrm{C}_{4}-\mathrm{C}_{6}\right)$}

La fraction légère de l'essence contient douze hydrocarbures identifiables et quantifiables appartenant aux familles des $n$ alcanes, méthyl- et diméthyl-alcanes, alcènes et cycloalcanes. La biodégradabilité des composés de cette fraction a été évaluée d'une part individuellement, puis en mélange (SolanoSerena et al., 2000b). Dans chaque cas, les hydrocarbures constituent la seule source de carbone pour la croissance des microorganismes.

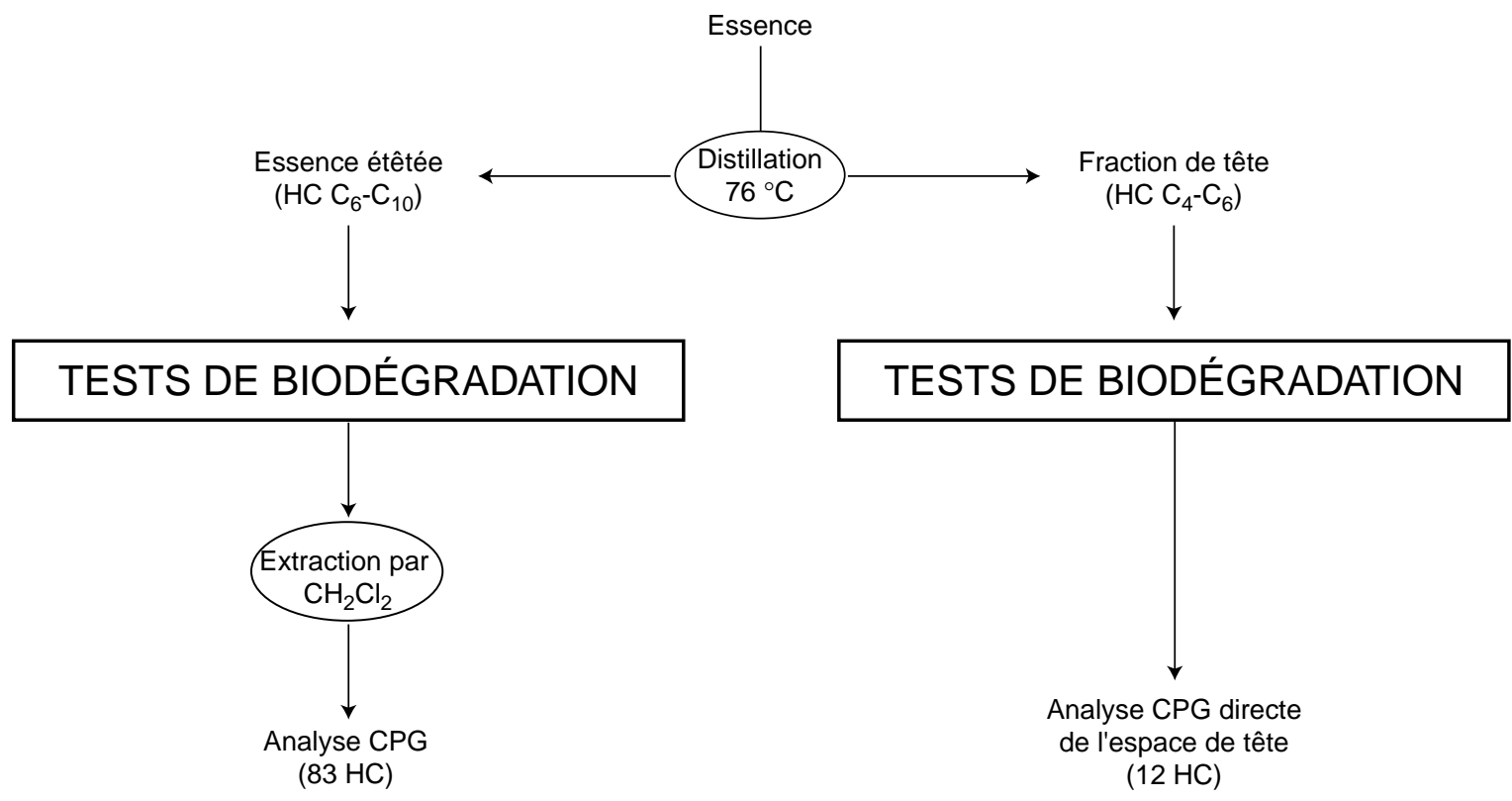

Figure 2

Stratégie utilisée pour l'étude de la biodégradabilité de l'essence. Strategy used to assess biodegradability of gasoline. 


\subsubsection{Dégradation des hydrocarbures individuels}

Le suivi de la dégradation des hydrocarbures individuels a été réalisé en dosant par CPG la consommation d'hydrocarbure d'une part et la production de $\mathrm{CO}_{2}$ d'autre part. $\mathrm{La}$ figure 3 montre l'exemple de l'isopentane (2-méthylbutane), composé très largement majoritaire de la fraction légère de l'essence. Cet hydrocarbure est complètement dégradé en douze jours, après une période de latence de cinq jours. La vitesse maximale de consommation est de $55 \mu \mathrm{mol} \cdot \mathrm{l}^{-1} \cdot \mathrm{h}^{-1}$. Les résultats concernant l'ensemble des douze composés de la fraction légère sont regroupés dans les tableaux 3 et 4 . Tous les composés sont dégradés par la microflore, avec des taux de minéralisation différents, à l'exception des 2,2-diméthylbutane et 2,3-diméthylbutane. La consommation des hydrocarbures démarre après une période de latence de cinq à six jours, excepté pour le 3-méthylpentane et le méthylcyclopentane pour lesquels cette période est plus longue. La vitesse maximale de dégradation du méthylcyclopentane est nettement inférieure à celle des autres composés.

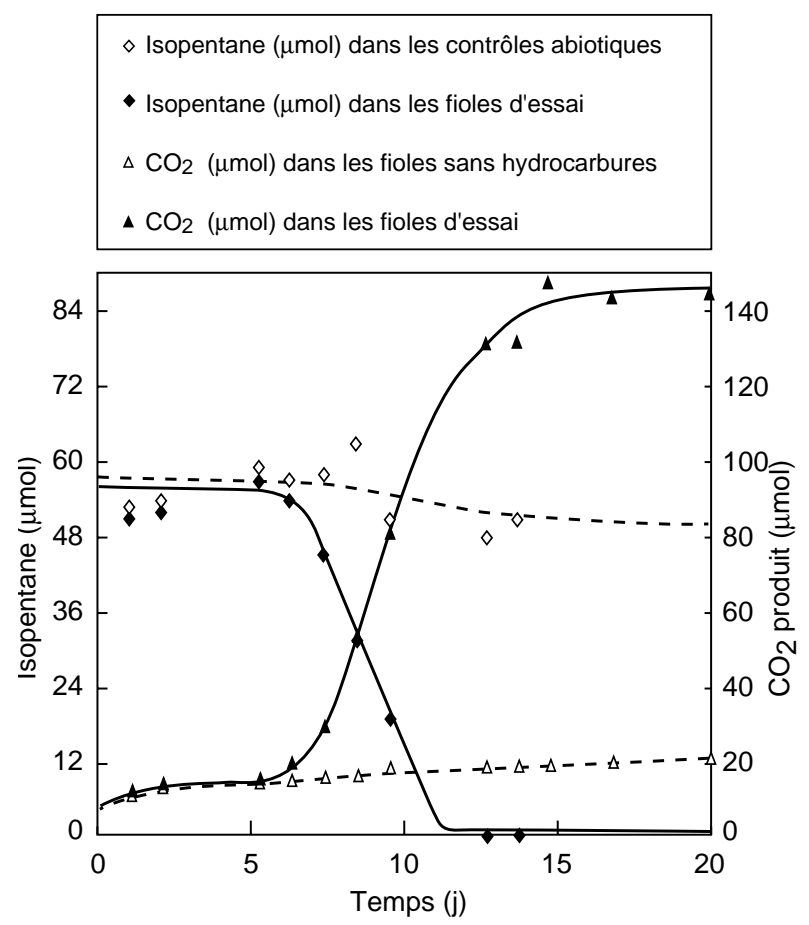

Figure 3

Cinétique de dégradation et de minéralisation de l'isopentane par des boues activées. L'isopentane constituait la seule source de carbone. Les conditions d'incubation et d'analyse par CPG sont décrites dans le texte.

Kinetics of degradation and mineralisation of isopentane by activated sludge. Conditions of incubation and GC analysis are described in the text.

\subsubsection{Dégradation de la fraction légère}

La même méthodologie a été utilisée pour évaluer la biodégradabilité de la fraction de tête de l'essence (suivi des hydrocarbures du mélange par CPG). Les taux de dégradation déterminés pour chacun des hydrocarbures sont présentés dans le tableau 5. En comparant les résultats de dégradation des hydrocarbures fournis en mélange et individuellement, on observe des différences très marquées pour les diméthylbutanes. Les cinétiques de dégradation du 2,2-diméthylbutane sont présentées sur la figure 4. Cet hydrocarbure est dégradé lorsqu'il est présent au sein du mélange, alors qu'il ne l'est pas lorsqu'il est fourni individuellement dans le milieu de culture. Sa consommation démarre après quinze jours d'incubation et reste incomplète. L'arrêt de la consommation du 2,2-diméthylbutane coïncide avec l'épuisement des autres hydrocarbures présents dans le mélange. Ces résultats indiquent l'existence d'une dégradation par cométabolisme. Des résultats similaires ont été observés pour le 2,3-diméthylbutane.

Les vitesses de dégradation des hydrocarbures sont très différentes selon que les composés sont fournis individuellement ou en mélange. Dans le premier cas, les substrats sont présents à des concentrations similaires et les différences entre les vitesses maximales de dégradation reflètent vraisemblablement l'activité de la microflore pour chaque hydrocarbure. Dans le deuxième cas, les vitesses apparaissent clairement corrélées aux pressions partielles des composés dans l'espace de tête (fig. 5). Ces résultats suggèrent que la cinétique de dégradation est contrôlée par le transfert entre les phases gazeuse et liquide. En effet, comme l'indiquent les constantes de Henry des douze hydrocarbures, dans les conditions d'incubation, les composés sont essentiellement présents dans la phase gazeuse des fioles (à plus de $99 \%)$.

\subsection{Biodégradabilité de l'essence étêtée $\left(C_{6}-C_{10}\right)$}

\subsubsection{Cinétique de biodégradation}

La biodégradabilité de la fraction plus lourde de l'essence a été tout d'abord étudiée de façon cinétique par respirométrie, en mesurant la consommation d'oxygène. La cinétique de dégradation se divise en deux phases (fig. 6). Une phase rapide de dégradation qui débute après $18 \mathrm{~h}$ de latence et qui se termine après $40 \mathrm{~h}$ d'incubation. Au cours de cette période, on observe un ralentissement de la consommation de l'oxygène après $34 \mathrm{~h}$ d'incubation. Les analyses chromatographiques ont montré que ce ralentissement correspondait à un épuisement du toluène et de l'éthylbenzène, qui sont les deux composés majoritaires de l'essence étêtée. Ils représentent en effet plus de $36 \%$ (en masse) de la fraction. La première phase est suivie d'une phase de dégradation lente au cours de laquelle la vitesse de consommation d'oxygène diminue de la $40^{\mathrm{e}}$ heure au $25^{\mathrm{e}}$ jour. La vitesse moyenne de 
TABLEAU 3

Utilisation d'hydrocarbures volatils individuels comme sources de carbone par des boues activées

Utilisation of individual volatile hydrocarbons of gasoline as carbon sources by activated sludge

\begin{tabular}{|c|c|c|c|c|}
\hline \multicolumn{2}{|c|}{ Hydrocarbures } & \multicolumn{2}{|c|}{$\begin{array}{l}\text { Quantité résiduelle* } \\
\text { (\% quantité initiale) }\end{array}$} & \multirow{2}{*}{$\begin{array}{c}\text { Taux de minéralisation } \\
*, * *(\%)\end{array}$} \\
\hline Famille & Nom & Témoins abiotiques & Essais & \\
\hline$n$-alcanes & $\begin{array}{l}\text { Propane } \\
\text { Pentane }\end{array}$ & $\begin{array}{l}96 \\
92\end{array}$ & $\begin{array}{l}0 \\
0\end{array}$ & $\begin{array}{l}57 \\
53\end{array}$ \\
\hline Isoalcanes & $\begin{array}{l}\text { 2-méthylpropane } \\
\text { 2-méthylbutane } \\
\text { 2-méthylpentane } \\
\text { 3-méthylpentane } \\
\text { 2,2-diméthylbutane } \\
\text { 2,3-diméthylbutane }\end{array}$ & $\begin{array}{c}91 \\
95 \\
80 \\
82 \\
89 \\
100\end{array}$ & $\begin{array}{c}0 \\
0 \\
0 \\
0 \\
86 \\
87\end{array}$ & $\begin{array}{c}49 \\
42 \\
34 \\
31 \\
0 \\
0\end{array}$ \\
\hline Cycloalcanes & Méthylcyclopentane & 122 & 3 & 62 \\
\hline
\end{tabular}

Chaque hydrocarbure est incubé dans des fioles séparées.

* Moyenne de deux fioles.

** Taux de minéralisation déterminé comme décrit précédemment.

\section{TABLEAU 4}

Caractéristiques cinétiques de l'utilisation d'hydrocarbures volatils individuels par des boues activées

Kinetic characteristics of the degradation of individual volatile hydrocarbons by activated sludge

\begin{tabular}{c|l|c|c}
\hline \multicolumn{2}{c|}{ Hydrocarbures } & Période de latence \\
Famille & \multicolumn{1}{c|}{ Nom } & $\begin{array}{c}\text { Vitesse maximale de dégradation } \\
\left(\mu \mathrm{mol} \cdot \mathrm{l}^{-1} \cdot \mathrm{h}^{-1}\right)\end{array}$ \\
\hline \multirow{2}{*}{$n$-alcanes } & Propane & 5,9 & 202 \\
& Pentane & 4,6 & 149 \\
& 2-méthylpropane & 5,7 & 67 \\
\multirow{3}{*}{ Isoalcanes } & 2-méthylbutane & 6,1 & 55 \\
& 2-méthylpentane & 6,3 & 69 \\
& 3-méthylpentane & 27,4 & 66 \\
& 2,2-diméthylbutane & - & - \\
\hline Cycloalcanes & 2,3-diméthylbutane & - & 15 \\
\hline
\end{tabular}

consommation d'oxygène est 40 fois plus faible que lors de la phase rapide.

Les hydrocarbures ont été dosés après les phases rapide et lente. Les profils chromatographiques obtenus sont présentés en figures $7 \mathrm{a}$ à $7 \mathrm{c}$. Durant la phase rapide, 24 composés identifiables, représentant plus de $74 \%$ (en masse) de l'essence, ont été consommés. Durant la phase lente, 45 composés identifiables, soit $20 \%$ seulement (en masse), ont été dégradés.

La dégradation a démarré dès le début de la phase rapide pour toutes les classes d'hydrocarbures ( $n$-alcanes, isoalcanes, cycloalcanes, alcènes, et aromatiques) (tableau 6). Les résultats montrent que les monoaromatiques se dégradent plus rapidement que les composés linéaires, branchés ou cycliques.
L'analyse des 83 hydrocarbures identifiables de la fraction étêtée (Solano-Serena et al., 1999b) a été réalisée grâce au logiciel Carburane (Durand et al., 1995 ; NF07_086). Tous les composés aromatiques sont très largement consommés, $\mathrm{y}$ compris les noyaux possédant des substitutions en ortho $(o-$ xylène) ou des noyaux tri- ou tétra-substitués. D'autre part, les alcanes linéaires, alcènes et cycloalcanes sont aussi très bien dégradés. Il apparaît que les structures les plus récalcitrantes, présentées en figure 8 , sont les alcanes branchés avec un atome de carbone quaternaire (2,2,4-triméthylpentane, 2,2,5-triméthylhexane), ou avec des groupements méthyles portés par des atomes de carbone consécutifs (2,3,4-triméthylpentane), ou avec ces deux particularités (2,3,3-triméthylpentane). 


\section{TABLEAU 5}

Dégradation de la fraction de tête de l'essence par des boues activées

Degradation of the light fraction of gasoline by activated sludge

\begin{tabular}{|c|c|c|c|c|}
\hline \multicolumn{2}{|c|}{ Hydrocarbures } & \multirow{2}{*}{$\begin{array}{l}\text { Concentration initiale* } \\
\qquad\left(\mathrm{mg} \cdot \mathrm{l}^{-1}\right)\end{array}$} & \multicolumn{2}{|c|}{$\begin{array}{l}\text { Quantité résiduelle** } \\
\text { (\% quantité initiale) }\end{array}$} \\
\hline Famille & Nom & & Témoins abiotiques & Essai \\
\hline$n$-alcanes & $\begin{array}{l}\text { Butane } \\
\text { Pentane } \\
\text { Hexane }\end{array}$ & $\begin{array}{c}32,9 \\
16,2 \\
6,2\end{array}$ & $\begin{array}{l}86 \\
84 \\
76\end{array}$ & $\begin{array}{l}0 \\
0 \\
0\end{array}$ \\
\hline Isoalcanes & $\begin{array}{l}\text { 2-méthylpropane } \\
\text { 2-méthylbutane } \\
\text { 2-méthylpentane } \\
\text { 3-méthylpentane } \\
\text { 2,2-diméthylbutane } \\
\text { 2,3-diméthylbutane }\end{array}$ & $\begin{array}{c}10,1 \\
100,6 \\
30,9 \\
19,3 \\
15,0 \\
13,4\end{array}$ & $\begin{array}{l}90 \\
87 \\
83 \\
84 \\
84 \\
82\end{array}$ & $\begin{array}{c}0 \\
0 \\
0 \\
0 \\
14 \\
0\end{array}$ \\
\hline Cycloalcanes & Méthylcyclopentane & 4,7 & 89 & 0 \\
\hline Alcènes & $\begin{array}{l}\text { Pentène-2-trans } \\
\text { 2-méthylbutène-2 }\end{array}$ & $\begin{array}{l}3,0 \\
4,1\end{array}$ & $\begin{array}{l}84 \\
88\end{array}$ & $\begin{array}{l}0 \\
0\end{array}$ \\
\hline
\end{tabular}

* mg de chaque hydrocarbure de la fraction par litre de milieu de culture.

** Moyenne de deux fioles, determinée après 34 jours d'incubation.

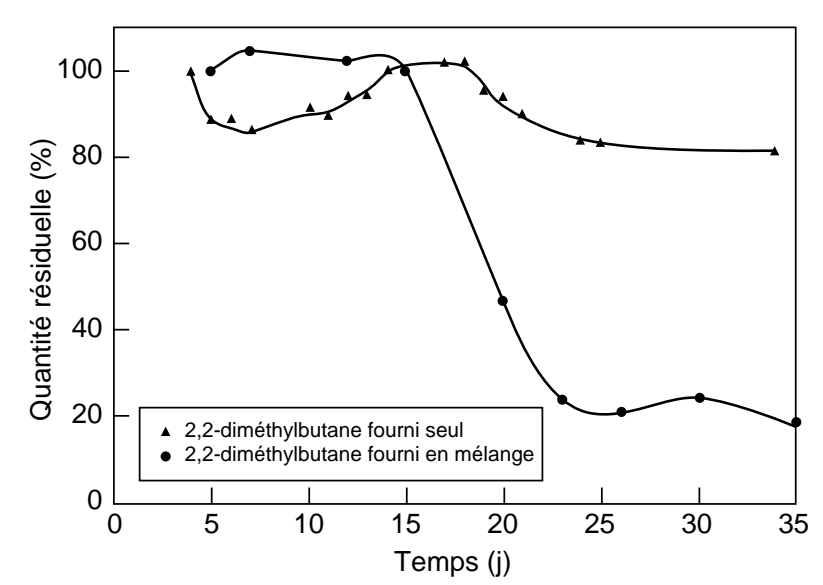

Figure 4

Cinétique de dégradation par les boues activées du 2,2diméthylbutane, seul ou dans la fraction légère de l'essence.

Degradation kinetics of 2,2-dimethylbutane, supplied as sole carbon source or in the light gasoline fraction mixture, by activated sludge.

\subsubsection{Bilan de biodégradation}

Le taux de dégradation global de l'essence étêtée atteint $94 \%$ après 25 jours. Un bilan de dégradation a été réalisé afin de connaître le devenir du carbone initialement présent dans les hydrocarbures de l'essence (tableau 7). Le bilan carbone indique que près de $62 \%$ de l'essence dégradée a été minéralisée (production de $\mathrm{CO}_{2}$ ) et que le reste a été utilisé pour la croissance des microorganismes de la microflore (production de biomasse).

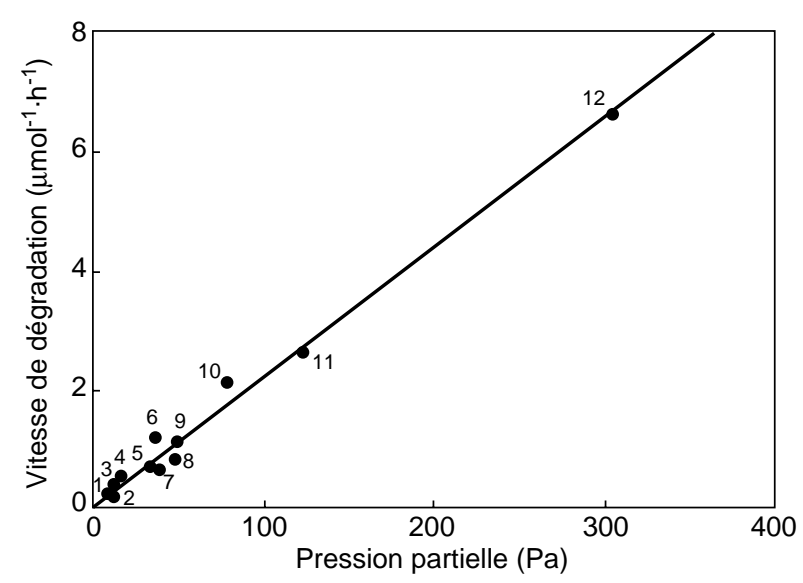

Figure 5

Relation entre la vitesse maximale de dégradation des hydrocarbures individuels de la fraction de tête et leur pression partielle dans le mélange.

Les vitesses maximales sont indiquées pour : $1:$ pentène- 2 trans ; 2 : méthylcyclopentane ; $3: 2$-méthyl butène-2; 4 : hexane ; $5:$ 2,3-diméthylbutane ; 6 : isobutane ; $7: 2,2$-diméthylbutane ; 8 : 3-méthylpentane ; 9 : pentane ; $10: 2$-méthylpentane ; 11 : butane ; 12 : isopentane.

Les pressions partielles sont calculées avec l'équation d'Antoine dont les coefficients sont donnés par Yaws (1992) pour chaque composé. Le coefficient de corrélation de la droite est de 0,989 .

Dependence of the maximal degradation velocity of individual hydrocarbons of the light gasoline fraction on their vapor pressure in the mixture.

Maximum velocities are indicated for: 1: pentene- 2 trans; 2: methylcyclopentane; 3: 2-methyl butene-2; 4: hexane; 5: 2,3-dimethylbutane; 6: isobutane; 7: 2,2-dimethylbutane; 8: 3-methylpentane; 9: pentane; 10: 2-methylpentane; 11: butane; 12: isopentane.

Partial pressures are calculated using Antoine's equation with the coefficient values for each compound given by Yaws (1992). The correlation coefficient of the straight line is 0.989. 


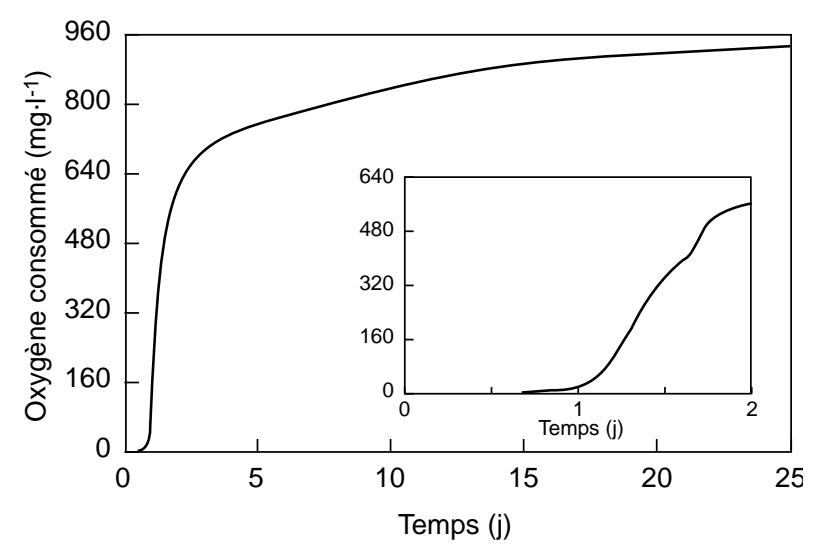

Figure 6

Cinétique de consommation d'oxygène durant la dégradation de l'essence. La consommation d'oxygène a été enregistrée pendant 25 jours par respirométrie électrolytique.

Kinetics of oxygen consumption during gasoline degradation. Oxygen uptake has been recorded during 25 days by electrolytic respirometry.

\subsection{Discussion}

La stratégie retenue pour l'étude a consisté à étudier la biodégradabilité de l'essence en système fermé et en présence d'un excès d'oxygène et de nutriments. Pour cela, une microflore de référence a été choisie. Il s'agit de boues activées de station d'épuration d'eaux usées urbaines. Ces boues, une fois centrifugées, débarrassées du surnageant et congelées, nous ont permis d'obtenir une excellente reproductibilité et un contrôle parfait de nos essais tout au long de notre étude. Cette microflore peut être, à juste titre, considérée comme microflore de référence puisque les tests normalisés, qui évaluent la biodégradabilité de molécules chimiques commerciales, ont recours classiquement à de tels inoculums. Par ailleurs, la coupe d'essence a été séparée par distillation en deux fractions et chacune analysée par la méthode appropriée. Ainsi, nous sommes parvenus à une détermination qualitative et quantitative, avec une bonne reproductibilité, des quelque cent composés majoritairement présents dans l'essence sous la forme de deux fractions séparées.

L'essence est hautement biodégradable. En utilisant la microflore de référence, $99 \%$ de la fraction légère et $94 \%$ de la fraction lourde sont dégradés après quatre à cinq semaines d'incubation en conditions non limitantes. Ces taux indiquent une diversité importante de la microflore car il est établi que la dégradation des alcanes et isoalcanes à courtes chaînes carbonées nécessite des microflores spécialisées (Patel et al., 1983 ; Woods et Murrel, 1989 ; Vestal, 1984). Les résultats confirment que les hydrocarbures constitutifs de l'essence sont dégradés par la microflore à des vitesses différentes. Les

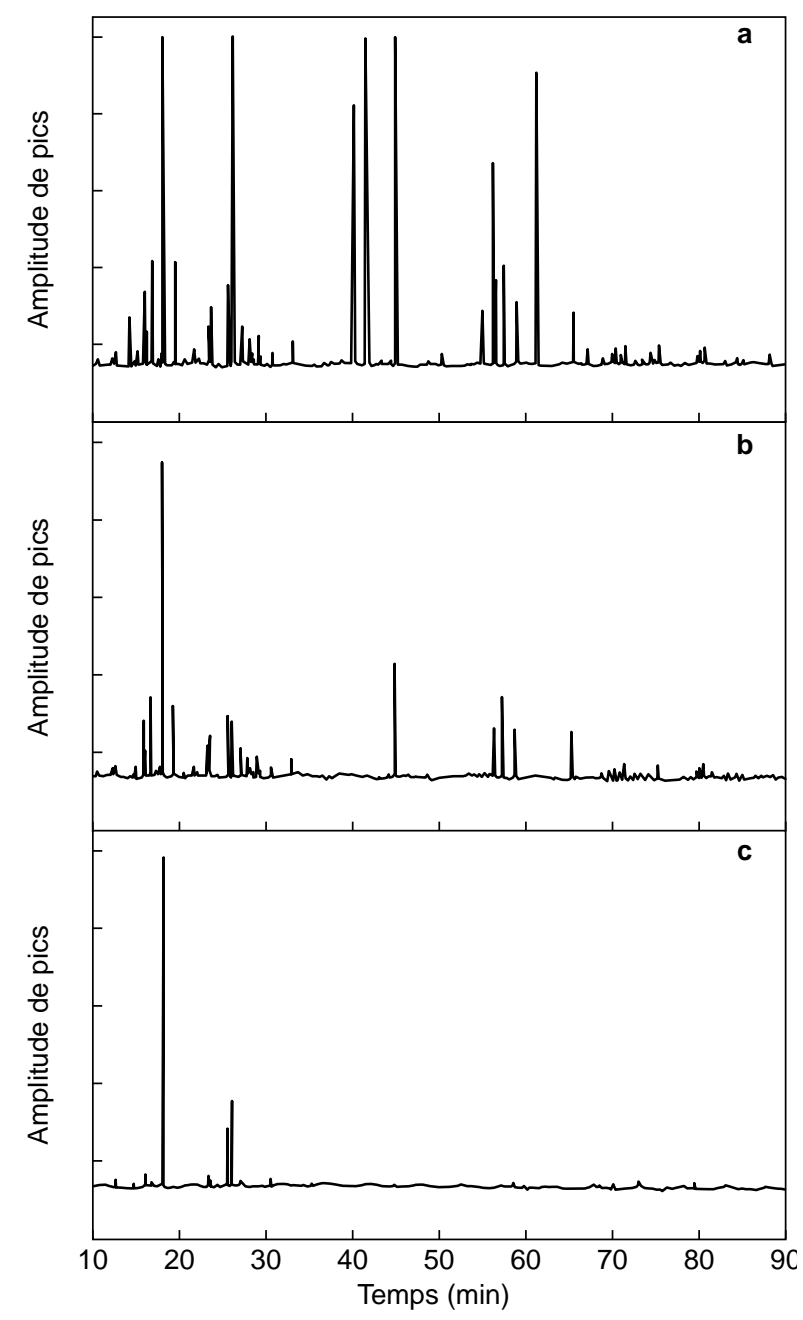

Figure 7

Profils chromatographiques des hydrocarbures résiduels de l'essence (fraction étêtée) après 2 et 25 jours d'incubation.

(a) Contrôle abiotique (fiole agitée de $500 \mathrm{ml}$ ) après 25 jours.

(b) Fiole d'essai (fiole respirométrique) après 2 jours.

(c) Fiole d'essai après 25 jours.

Chromatographic patterns of residual hydrocarbons of gasoline (topped fraction) after 2 and 25 days of incubation.

(a) Abiotic control (stirred flask of $500 \mathrm{ml}$ ) after 25 days.

(b) Assay flask (respirometric flask) after 2 days.

(c) Assay flask after 25 days.

BTEX (sauf l'o-xylène) sont consommés très vite et les $n$-alcanes sont aussi rapidement métabolisés, comme divers travaux l'avaient déjà montré (Zhou et Crawford, 1995 ; Yerushalmi et Guiot, 1998). En revanche, la dégradation des isoalcanes démarre après celle des $n$-alcanes, s'effectue sur une durée d'un mois et certains d'entre eux ne sont pas complètement métabolisés. Nielsen et al. (1996) avaient observé des phénomènes similaires sur gazole. 
TABLEAU 6

Dégradation des classes d'hydrocarbures de l'essence étêtée par des boues activées après 2 et 25 jours d'incubation

Degradation of hydrocarbon classes of topped gasoline by activated sludge after 2 and 25 days of incubation

\begin{tabular}{|c|c|c|c|}
\hline \multirow{2}{*}{ Classes d'hydrocarbures } & \multirow{2}{*}{$\begin{array}{l}\text { Concentration dans } \\
\text { l'essence }\left(\mathrm{mg} \cdot \mathrm{g}^{-1}\right)\end{array}$} & \multicolumn{2}{|c|}{ Taux de dégradation* $(\%)$} \\
\hline & & Après 2 jours** & Après 25 jours*** \\
\hline Aromatiques & 789 & 88 & $99 \pm 1$ \\
\hline Alcanes ramifiés & 165 & 14 & $74 \pm 5$ \\
\hline Alcanes linéaires & 23 & 17 & $92 \pm 1$ \\
\hline Alcanes cycliques & 17 & 10 & $99 \pm 1$ \\
\hline Alcènes & 6 & 71 & $99 \pm 1$ \\
\hline
\end{tabular}

* Le taux de dégradation est déterminé comme le ratio de la quantité d'hydrocarbure dégradé sur la quantité initiale.

** Moyenne de deux fioles.

*** Moyenne de cinq fioles. Les déviations standard sont indiquées.

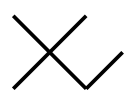

2,2-diméthylbutane

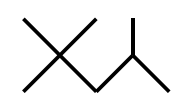

2,2,4-triméthylpentane

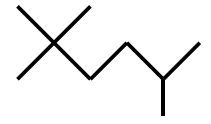

2,2,5-triméthylhexane

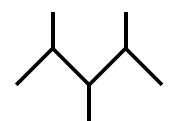

2,3,4-triméthylpentane

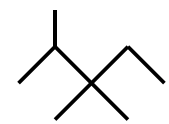

2,3,3-triméthylpentane
Figure 8

Structure des hydrocarbures récalcitrants.

Chemical structures of recalcitrant hydrocarbons.

TABLEAU 7

Bilan carbone de la dégradation de l'essence étêtée par des boues activées Carbon balance of gasoline degradation by activated sludge

\begin{tabular}{l|c|c}
\hline $\begin{array}{l}\text { Substrats } \\
\text { ou produits }\end{array}$ & $\begin{array}{c}\text { Quantité initiale } \\
\left(\mathrm{mg} \mathrm{C} \cdot l^{-1}\right)\end{array}$ & $\begin{array}{c}\text { Quantité finale } \\
\left(\mathrm{mg} \mathrm{C} \cdot \mathrm{l}^{-1}\right)\end{array}$ \\
\hline Essence & 357 & $18^{* *}$ \\
Biomasse* & 39 & 165 \\
$\mathrm{CO}_{2}$ & 0 & $204^{* * *}$ \\
Total carbone & 396 & 387 \\
\hline
\end{tabular}

Les quantités finales sont déterminées après 25 jours d'incubation à $30^{\circ} \mathrm{C}$.

* Les proportions initiale et finale de carbone dans la biomasse étaient respectivement de 47 et $51,5 \%$.

** Moyenne de cinq fioles. La déviation standard est de \pm 4 .

**** Moyenne de trois fioles. La déviation standard est de \pm 30 .
Les alcanes ramifiés incomplètement dégradés renseignent sur les structures moléculaires présentant une résistance à la biodégradation : celles qui comportent des atomes de carbone quaternaires ou encore des atomes de carbone consécutifs portant un groupement méthyle (fig. 8). Divers auteurs avaient déjà évoqué la résistance à la biodégradation des composés multibranchés (Thijsse et Zwilling-De Vries, 1959 ; Mc Kenna, 1972 ; Pirnik et al., 1974 ; Jamison et al., 1975 ; Pirnik, 1977).

Une caractéristique importante du processus de biodégradation des mélanges d'hydrocarbures est l'intervention de cométabolisme. Certains hydrocarbures, qui ne sont pas attaqués lorsqu'ils sont fournis comme seule source de carbone, sont attaqués dès lors qu'ils sont fournis à la microflore au sein d'un mélange, les autres composés du mélange servant de substrat de croissance. Ce phénomène, important dans la dégradation des hydrocarbures, a été mis en évidence ici pour les 2,2- et 2,3-diméthylbutanes.

\section{CAPACITÉ DE DÉGRADATION DES MICROFLORES DE L'ENVIRONNEMENT}

\subsection{Mise au point et validation d'une méthodologie}

Comme déjà mentionné, un deuxième point important à étudier en cas de déversement accidentel concerne les capacités de dégradation de la microflore présente sur le site pollué visà-vis du polluant. Ces connaissances permettent en effet de déterminer le potentiel de biodégradation in situ, c'est-à-dire de connaître les possibilités de dépollution par atténuation naturelle.

Les résultats présentés précédemment indiquent que la biodégradabilité de l'essence est très bonne. Cependant, des limitations concernant la dégradation de certains isoalcanes apparaissent ; leur dégradation nécessite en effet l'intervention 
de phénomènes de cométabolisme. Ces limitations, mises en évidence avec la microflore de référence, étaient-elles similaires avec d'autres microflores?

Ainsi, nous avons évalué les capacités de dégradation de microflores présentes dans des échantillons provenant d'environnements différents (forêt, jardin, sol pollué, eau de nappe phréatique polluée). Les essais ont été menés, comme précédemment, dans des conditions non limitantes en ce qui concerne particulièrement la disponibilité en nutriments et en oxygène. Dans cette partie de l'étude, seule l'essence étêtée a été prise en compte car c'est elle qui représente le risque majeur pour l'environnement en cas de pollution. L'analyse d'une coupe pétrolière telle que l'essence étêtée est longue et fastidieuse en raison de la présence de nombreux hydrocarbures, qui contribuent de façon très inégale à sa composition : 180 hydrocarbures sur 203 sont présents dans l'essence étêtée à une concentration inférieure à $0,5 \%$ en masse. Pour ces raisons, une méthodologie permettant l'évaluation plus rapide des capacités de dégradation de microflores de l'environnement a été développée ; elle met en œuvre un mélange, appelé mélange modèle d'essence GM23. Il contient les 23 composés majoritaires de l'essence étêtée qui, ensemble, représentent $90 \%$ de la fraction étêtée. Les 23 hydrocarbures sont présents à des concentrations équivalentes au sein du mélange modèle d'essence (fig. 9).

La validation de la méthodologie mise au point a été réalisée grâce à deux expériences menées en parallèle, mettant en jeu une même microflore avec l'essence étêtée d'une part et le mélange modèle GM23 d'autre part (Solano-Serena et al., 1999a). Les taux de dégradation des 23 hydrocarbures présents dans le mélange ont été déterminés (tableau 8). Ces taux sont similaires, que l'on considère l'essence étêtée ou le mélange modèle GM23. Ces résultats indiquent que, bien que l'essence étêtée contienne 83 hydrocarbures identifiables, l'étude des 23 composés majoritaires donne une très bonne représentation de la biodégradation de l'essence étêtée.

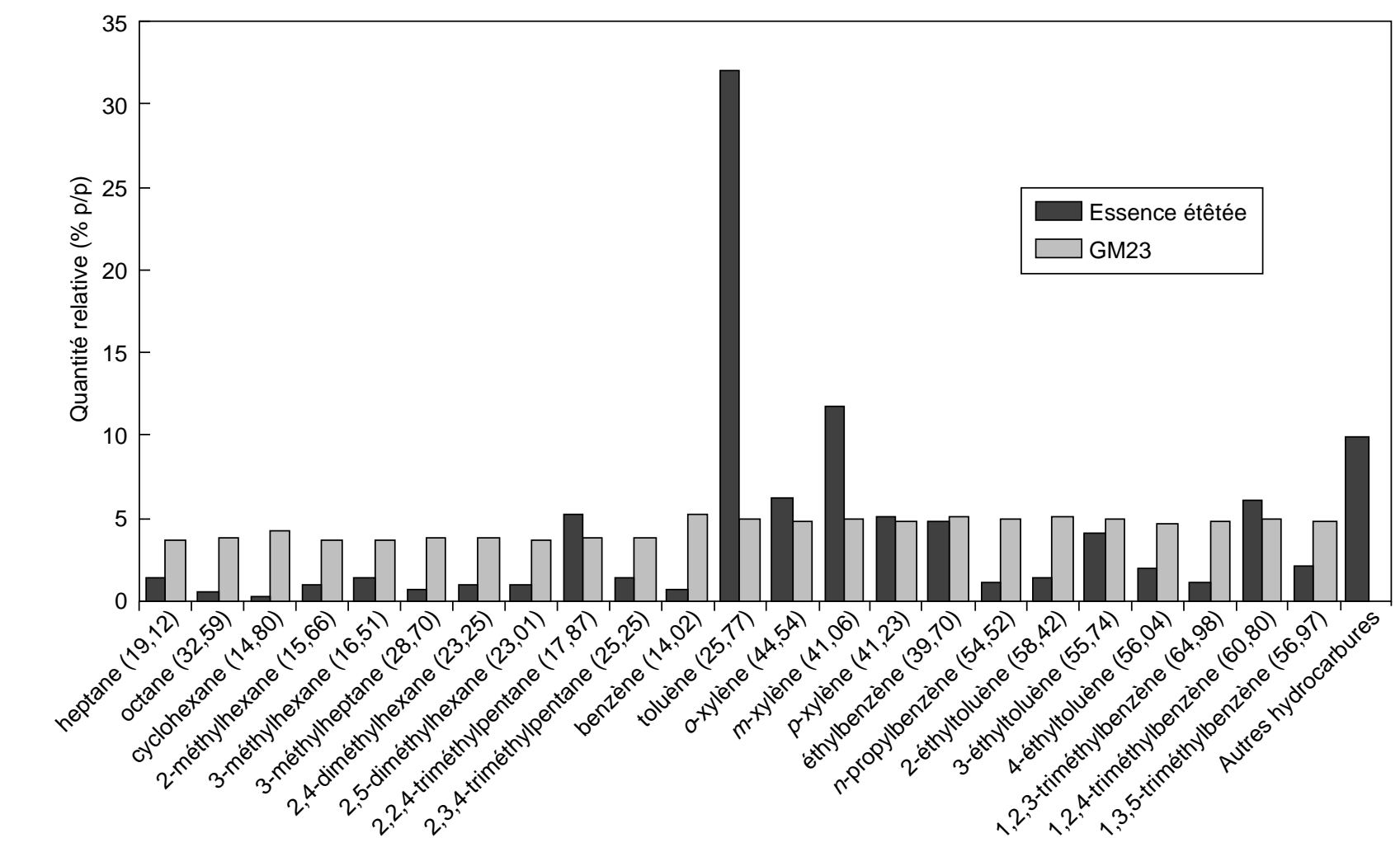

$\overline{n \text {-alcanes }}$ Alcanes branchés

Hydrocarbures aromatiques

Figure 9

Composition relative de l'essence étêtée et du mélange modèle d'essence GM23. Les temps de rétention (en min) des hydrocarbures dans les conditions de CPG utilisées sont indiqués entre parenthèses.

Relative composition of topped gasoline and of gasoline model mixture GM23. Retention times (in min) of hydrocarbons in the GC conditions used are indicated in parentheses. 
Seules quelques différences ont été observées. En particulier, les taux de dégradation des triméthylpentanes sont différents d'une expérience à l'autre, probablement à cause des concentrations qui ne sont pas identiques dans les deux milieux.

Ces résultats montrent que les capacités de dégradation de microflores de l'environnement peuvent être correctement évaluées avec le mélange modèle d'essence GM23.

TABLEAU 8

Dégradation de l'essence étêtée et du GM23 par des boues activées Degradation of topped gasoline and GM23 by activated sludge

\begin{tabular}{|c|c|c|}
\hline \multirow[b]{2}{*}{ Composés } & \multicolumn{2}{|c|}{ Taux de dégradation* $(\%)$} \\
\hline & Essence étêtée & $\begin{array}{l}\text { Mélange modèle } \\
\text { d'essence GM23 }\end{array}$ \\
\hline$n$-heptane & 100 & 100 \\
\hline$n$-octane 100 & 100 & \\
\hline 2-méthylhexane & 100 & 100 \\
\hline 3-méthylhexane & 99 & 100 \\
\hline 3-méthylheptane & 100 & 100 \\
\hline 2,4-diméthylhexane & 92 & 100 \\
\hline 2,5-diméthylhexane & 92 & 100 \\
\hline 2,2,4-triméthylpentane & 50 & 28 \\
\hline 2,3,4-triméthylpentane & 69 & 26 \\
\hline Cyclohexane & 100 & 100 \\
\hline Benzène & 100 & 100 \\
\hline Toluène & 100 & 100 \\
\hline Éthylbenzène & 100 & 100 \\
\hline$m$-xylène & 100 & 100 \\
\hline$p$-xylène & 100 & 100 \\
\hline$o$-xylène & 100 & 100 \\
\hline$n$-propylbenzène & 100 & 100 \\
\hline 1,2,3-triméthylbenzène & 100 & 100 \\
\hline 1,2,4-triméthylbenzène & 100 & 100 \\
\hline 1,3,5-triméthylbenzène & 95 & 100 \\
\hline 1-méthyl 2-éthylbenzène & 88 & 100 \\
\hline 1-méthyl 3-éthylbenzène & 100 & 100 \\
\hline 1-méthyl 4-éthylbenzène & 100 & 100 \\
\hline Total pour 23 composés & $96^{* *}$ & 95 \\
\hline
\end{tabular}

* Moyenne de deux fioles.

** Le taux de dégradation de toute la fraction est de $94 \%$.

\subsection{Distribution des capacités de dégradation dans l'environnement}

L'utilisation de la méthodologie a permis d'évaluer les capacités de dégradation des microflores provenant de neuf échantillons différents (Solano-Serena et al., 2000c). Les résultats de dégradation sont présentés dans le tableau 9. Les taux de dégradation mesurés pour chacun des 23 composés sont regroupés par sous-famille d'hydrocarbures, $n$-alcanes, méthylalcanes, diméthylalcanes, triméthylalcanes, etc., de manière à faciliter les comparaisons entre les différentes microflores.
Les capacités de dégradation sont globalement très bonnes puisque les taux de dégradation atteignent au moins $85 \%$ pour huit échantillons sur neuf testés. Le dernier échantillon (microflore 8) semble être microbiologiquement inactif, probablement à cause d'une concentration en BTEX (liée à la pollution endogène à l'échantillon) trop forte, qui inhibe les microorganismes.

Pour tous les autres échantillons, la dégradation des $n$ alcanes, BTEX, $n$-propylbenzènes et éthyltoluènes est totale. Les microflores 2 et 8 sont les seuls échantillons pour lesquels la dégradation des méthylalcanes, diméthylalcanes et triméthylbenzènes reste incomplète. La limitation des capacités de dégradation est plus marquée pour les triméthylpentanes et le cyclohexane. En effet, la dégradation du cyclohexane n'est pas totale avec les microflores provenant d'environnements non pollués ( 2 et 3 ) et avec une microflore de sol pollué (8). La déficience des microflores vis-à-vis de la dégradation des triméthylpentanes est plus répandue que visà-vis du cyclohexane puisque cinq microflores sur neuf dégradent de façon incomplète les triméthylalcanes.

Afin de confirmer que l'absence de dégradation est liée à une déficience microbiologique, la microflore native du sol de forêt (2) a été renforcée avec une microflore apte à dégrader le cyclohexane et une microflore capable de dégrader le 2,2,4-triméthylpentane, qui avaient été sélectionnées par ailleurs (Solano-Serena et al., 2000d). Un test de dégradation mettant en œuvre cette microflore microbiologiquement renforcée et le mélange GM23 a montré une dégradation totale de tous les composés du mélange modèle d'essence. Les taux de minéralisation sont plus élevés avec la microflore renforcée qu'avec la microflore native puisqu'ils atteignent respectivement 58 et $45 \%$ (Solano-Serena et al., 1998).

\subsection{Discussion}

Les capacités intrinsèques des microflores de l'environnement (sols et nappe phréatique) ont été évaluées avec la méthodologie mettant en œuvre le mélange modèle d'essence GM23. À l'instar de la microflore de boues activées de station d'épuration, les microflores de sols présentent une capacité de dégradation large (85\% au minimum). Les triméthylpentanes et le cyclohexane apparaissent comme les composés les plus résistants à la biodégradation. Ridgway et al. (1990) avaient mentionné la difficulté à isoler des souches dégradant le cyclohexane ou le 2,2,4-triméthylpentane. La déficience des microflores pour la dégradation des triméthylpentanes est cependant plus répandue que pour la dégradation du cyclohexane. Le cyclohexane peut en effet se dégrader par cométabolisme (Beam et Perry, 1973 ; De Klerk et Van der Linden, 1974), avec une multitude de composés servant de substrat de croissance (Trudgill, 1984 ; Perry, 1979, 1984), ou encore par commensalisme (Beam et Perry, 1974a, 1974b ; Lloyd-Jones et Trudgill, 1989). L'absence de microflores spécifiques semble expliquer les résultats 
TABLEAU 9

Dégradation du mélange modèle d'essence GM23 par différentes microflores

Biodegradation of the gasoline model mixture GM23 by various microflorae

\begin{tabular}{|c|c|c|c|c|c|c|c|c|c|}
\hline \multirow{2}{*}{ Hydrocarbures } & \multicolumn{9}{|c|}{ Dégradation des hydrocarbures pour l'échantillon* } \\
\hline & 1 & 2 & 3 & 4 & 5 & 6 & 7 & 8 & 9 \\
\hline$n$-alcanes & 100 & 100 & 99 & 99 & 100 & 100 & $0 * *$ & 100 & 100 \\
\hline Méthylalcanes & 100 & 94 & 100 & 100 & 100 & 100 & $0 * *$ & 97 & 100 \\
\hline Diméthylalcanes & 100 & 90 & 100 & 100 & 100 & 100 & $0 * *$ & 95 & 100 \\
\hline Triméthylalcanes & 27 & 14 & 28 & 76 & 100 & 100 & $0 * *$ & 17 & 100 \\
\hline Cyclohexanes & 100 & 29 & 75 & 99 & 100 & 100 & $0 * *$ & 85 & 100 \\
\hline $\begin{array}{l}\text { BTEX, } n \text {-propylbenzènes, } \\
\text { éthyltoluènes }\end{array}$ & 100 & 100 & 100 & 100 & 100 & 100 & $0 * *$ & 93 & 100 \\
\hline Triméthylbenzènes & 100 & 96 & 100 & 100 & 100 & 100 & $0 * *$ & 76 & 100 \\
\hline GM23 & 95 & 89 & 94 & 98 & 100 & 100 & $0 * *$ & 85 & 100 \\
\hline
\end{tabular}

1 Boues activées de station d'épuration urbaine.

2 Sol superficiel de forêt d'épicéas.

3 Sol de jardin.

4 Sable pollué par essence.

5 Sol pollué par gazole $\left(2 \mathrm{mg} \cdot \mathrm{g}^{-1}\right)$.

* Moyenne de deux essais, en \% de la quantité initiale.

** La quantité d'hydrocarbures dosée est supérieure à cause de la pollution endogène.

observés puisque le renforcement d'une microflore indigène déficiente, simultanément par une microflore dégradant l'isooctane (2,2,4-triméthylpentane) et par une microflore dégradant le cyclohexane, conduit à une dégradation totale du mélange modèle GM23.

Par ailleurs, il est bien connu que la présence de polluants se traduit par une adaptation des microflores avec un enrichissement quantitatif en microorganismes dégradeurs (Horowitz et Atlas, 1977). On constate ici que cette adaptation conduit à un élargissement des capacités de dégradation. La dégradation observée avec ces microflores est quasi totale dans la plupart des essais effectués. La synergie ou le commensalisme entre les différentes espèces de la population bactérienne sont susceptibles de jouer un rôle aussi important que le cométabolisme au cours de la biodégradation.

Enfin, les résultats obtenus avec les microflores de sols pollués nous indiquent qu'une microflore de station d'épuration, bien que très performante, ne doit pas constituer l'unique microflore pour l'évaluation de la biodégradabilité intrinsèque d'un polluant, même si celle-ci est importante. En fait, dans le cas de l'essence, la biodégradabilité intrinsèque est quasi totale.

\section{DÉGRADATION DES HYDROCARBURES RÉCALCITRANTS PAR MYCOBACTERIUM AUSTROAFRICANUM IFP 2173}

\subsection{Présentation}

Nos études sur la biodégradabilité de l'essence ont montré que certains hydrocarbures sont plus résistants à la biodégradation.
6 Sol pollué par gazole $\left(31 \mathrm{mg} \cdot \mathrm{g}^{-1}\right)$.

7 Argile polluée par BTEX.

8 Sable pollué par kérosène.

9 Eau de nappe phréatique polluée par essence.

Certaines microflores de l'environnement sont déficientes pour la dégradation des isoalcanes, en particulier les triméthylpentanes, ainsi que pour la dégradation du cyclohexane. Des phénomènes de cométabolisme permettent, dans certains cas, une dégradation des hydrocarbures récalcitrants. L'utilisation de microflores spécialisées, quand elles existent, constitue un autre aspect très intéressant. Elle permet d'approfondir les connaissances concernant la biodégradation des hydrocarbures et elle peut conduire à la mise au point de procédés améliorés de biorestauration. Nous avons donc cherché à sélectionner des microflores spécialisées dans la dégradation des composés récalcitrants, à partir de divers échantillons de sol.

La sélection de populations microbiennes à partir d'échantillons de terre n'est pas aisée puisque la croissance bactérienne est difficile à observer visuellement. Pour cette raison, nous avons suivi la production de $\mathrm{CO}_{2}$ au cours du temps pour détecter la croissance microbienne et ainsi sélectionner des populations et isoler des souches pures (Solano-Serena $e t$ al., 2000d). L'une d'entre elles (souche IFP 2173) est capable de croissance sur le 2,2,4-triméthylpentane (isooctane). L'isooctane étant l'isoalcane le plus abondant de l'essence étêtée et apparaissant comme un des plus récalcitrants, nous avons par la suite étudié les capacités de dégradation de cette souche et ses capacités de cométabolisme pour différents hydrocarbures, en particulier pour la dégradation du cyclohexane.

La souche IFP 2173 a tout d'abord été caractérisée par ses caractères phénotypiques. Le séquençage du gène codant pour l'ARN $16 \mathrm{~S}$ a permis ensuite de l'identifier comme une souche de Mycobacterium austroafricanum (Solano-Serena et al., 2000a). 
TABLEAU 10

Dégradation d'hydrocarbures individuels par M. austroafricanum IFP 2173

Degradation spectrum of individual hydrocarbons by M. austroafricanum IFP 2173

\begin{tabular}{|c|c|c|c|}
\hline Classes & Hydrocarbures & $\begin{array}{c}\text { Taux de dégradation* } \\
(\%)\end{array}$ & $\begin{array}{c}\text { Taux de minéralisation* } \\
(\%)\end{array}$ \\
\hline$n$-alcanes & $\begin{array}{l}\text { Propane } \\
\text { Butane } \\
\text { Pentane } \\
\text { Heptane } \\
\text { Octane } \\
\text { Decane } \\
\text { Hexadecane }\end{array}$ & $\begin{array}{c}0 \\
47 \\
100 \\
100 \\
100 \\
100 \\
88\end{array}$ & $\begin{array}{c}0 \\
14 \\
57 \\
41 \\
36 \\
42 \\
48\end{array}$ \\
\hline Méthylalcanes & $\begin{array}{l}\text { 2-méthylpropane } \\
\text { 2-méthylbutane } \\
\text { 2-méthylpentane } \\
\text { 3-méthylpentane } \\
\text { 2-méthylhexane } \\
\text { 3-méthylhexane } \\
\text { 2-méthylheptane } \\
\text { 3-méthylheptane } \\
\text { 2-méthyloctane }\end{array}$ & $\begin{array}{c}41 \\
57 \\
100 \\
100 \\
100 \\
100 \\
100 \\
100 \\
100\end{array}$ & $\begin{array}{c}4 \\
83 \\
59 \\
61 \\
58 \\
55 \\
46 \\
39 \\
37 \\
\end{array}$ \\
\hline Diméthylalcanes & $\begin{array}{l}\text { 2,2-diméthylbutane } \\
\text { 2,3-diméthylbutane } \\
\text { 2,2-diméthylpentane } \\
\text { 2,3-diméthylpentane } \\
\text { 2,4-diméthylpentane } \\
\text { 3,3-diméthylpentane } \\
\text { 2,2-diméthylhexane } \\
\text { 2,4-diméthylhexane } \\
\text { 2,5-diméthylhexane } \\
\text { 3,4-diméthylhexane }\end{array}$ & $\begin{array}{c}2 \\
14 \\
100 \\
100 \\
100 \\
34 \\
27 \\
100 \\
100 \\
100\end{array}$ & $\begin{array}{c}0 \\
39 \\
52 \\
45 \\
42 \\
<1 \\
7 \\
39 \\
55 \\
48\end{array}$ \\
\hline Triméthylalcanes & $\begin{array}{l}\text { 2,2,4-triméthylpentane } \\
\text { 2,3,4-triméthylpentane } \\
\text { 2,2,4-triméthylhexane }\end{array}$ & $\begin{array}{l}100 \\
87 \\
28\end{array}$ & $\begin{array}{c}46 \\
5 \\
<1\end{array}$ \\
\hline Autres isoalcanes & Pristane & 89 & 60 \\
\hline Alcanes cycliques & $\begin{array}{l}\text { Méthylcyclopentane } \\
\text { Cyclohexane }\end{array}$ & $\begin{array}{c}33 \\
0\end{array}$ & $\begin{array}{l}5 \\
0\end{array}$ \\
\hline Aromatiques & $\begin{array}{l}\text { Benzène } \\
\text { Toluène } \\
\text { Éthylbenzène } \\
n \text {-propylbenzène } \\
o \text {-xylène } \\
m \text {-xylène } \\
p \text {-xylène } \\
\text { 2-éthyltoluène } \\
\text { 3-éthyltoluène } \\
\text { 4-éthyltoluène }\end{array}$ & $\begin{array}{c}0 \\
98 \\
0 \\
0 \\
0 \\
100 \\
97 \\
0 \\
0 \\
0\end{array}$ & $\begin{array}{c}0 \\
30 \\
0 \\
0 * * \\
0 * * \\
50 \\
59 \\
0 * * \\
0 * * \\
0 * *\end{array}$ \\
\hline Éthers et alcools & $\begin{array}{l}\text { Éthyl tert-butyl éther } \\
\text { Méthyl tert-butyl éther } \\
\text { Méthyl tert-amyl éther } \\
\text { tert-butyl alcool }\end{array}$ & $\begin{array}{c}81 \\
32 \\
51 \\
0\end{array}$ & $\begin{array}{c}7 \\
<1 \\
< \\
< \\
0\end{array}$ \\
\hline
\end{tabular}

* Moyenne de deux essais. Les hydrocarbures dosés dans les témoins abiotiques correspondaient à la quantité théorique à $\pm 10 \%$ présente dans les $5 \mu$ introduits dans les fioles.

** Production de $\mathrm{CO}_{2}$ inférieure aux témoins de respiration endogène. 


\subsection{Dégradation d'hydrocarbures individuels}

Les capacités de dégradation de la souche ont été évaluées en déterminant la dégradation et la minéralisation des hydrocarbures. Les composés testés sont les principaux hydrocarbures présents dans l'essence (tableau 10).

Il apparait que M. austroafricanum IFP 2173 possède un large spectre de dégradation. Cette souche est capable de dégrader et minéraliser, d'une part, diverses structures moléculaires ( $n$-alcanes, isoalcanes, monoaromatiques ou composés oxygénés comme les éthers-carburants) et, d'autre part, une large gamme de tailles de chaînes carbonées (5 à 16 atomes de carbone). Les composés possédant des chaînes carbonées plus courtes (propane, butane ou isobutane) restent non ou partiellement dégradés.

La propriété la plus intéressante de la souche concerne sa capacité de dégradation des alcanes ramifiés. Tous les composés monométhylés et la plupart des diméthylés sont dégradés, même les composés antéiso-branchés connus pour bloquer la dégradation par $\beta$-oxydation (Schaeffer et al., 1979). Pour les hydrocarbures possédant un atome de carbone quaternaire, la position de cet atome dans la chaîne carbonée apparaît très importante. Par exemple, les composés tels que le 2,2-diméthylbutane, le 3,3-diméthylpentane et le 2,2-diméthylhexane sont peu dégradés, alors que le 2,2-diméthylpentane est bien minéralisé. Des observations similaires peuvent être faites pour les triméthylalcanes.

Les alcanes cycliques sont non ou peu dégradés. Parmi les composés aromatiques, quelques-uns ne sont pas minéralisés (benzène, éthylbenzène) et d'autres ont un effet inhibiteur sur la respiration endogène.

Concernant enfin la dégradation des éthers, les taux de dégradation sont importants mais les taux de minéralisation restent très faibles.

\subsection{Dégradation de mélanges d'hydrocarbures}

Les capacités dégradatives de la souche IFP 2173 ont aussi été évaluées sur des mélanges d'hydrocarbures afin de permettre des interactions entre substrats, telles que la compétition ou le cométabolisme, comme mis en évidence par Chang et al. (1992) pour la dégradation des BTEX. Deux mélanges modèles ont été utilisés : un mélange modèle de la fraction légère de l'essence, le LFM9, et un mélange modèle de l'essence étêtée, le GM23.

La dégradation du mélange LFM9 est modérée (39\%) puisque le butane et l'isobutane (2-méthylpropane) ne sont pas dégradés (tableau 11). La comparaison avec les taux de dégradation observés en incubations individuelles suggère l'existence de phénomènes de compétition (l'isobutane et le butane sont dégradés quand ils sont fournis individuellement et ne le sont pas en mélange) ainsi que l'existence de phénomènes de cométabolisme (les 2,2-, 2,3-diméthylbutanes et le méthylcyclopentane ont des taux de dégradation plus importants en mélange).

La dégradation du mélange modèle de l'essence étêtée (GM23) atteint $86 \%$ (tableau 12). Tous les composés qui étaient dégradés lorsqu'ils étaient fournis individuellement sont dégradés en mélange. Il n'existe pas de phénomène de compétition entre les substrats. Les composés qui étaient inhibiteurs aux concentrations mises en œuvre dans les tests individuels ( $n$-propylbenzène, éthyltoluènes et $o$-xylène) sont dégradés dans le mélange où leur concentration est plus faible (13-20 mg.1 $\mathrm{l}^{-1}$ au lieu de $350 \mathrm{mg} \cdot \mathrm{l}^{-1}$ ). Enfin, parmi les composés non dégradés dans les tests individuels, le benzène n'est pas dégradé en mélange alors que l'éthylbenzène et le cyclohexane sont consommés. Ces résultats suggèrent que la dégradation de ces composés met aussi en jeu des phénomènes de cométabolisme.

TABLEAU 11

Biodégradation du mélange modèle de la fraction de tête (LFM9) par M. austroafricanum IFP 2173

Biodegradation of the light-fraction model (LFM9) by M. austroafricanum IFP 2173

\begin{tabular}{l|c|c}
\hline \multicolumn{1}{c|}{ Hydrocarbures } & $\begin{array}{c}\text { Taux de dégradation } * *, * * * \\
(\%)\end{array}$ \\
\hline Butane & 120,5 & 6 \\
Pentane & 67,9 & 86 \\
2-méthylpropane & 120,5 & 0 \\
2-méthylbutane & 66,7 & 42 \\
2-méthylpentane & 72,9 & 100 \\
3-méthylpentane & 74,4 & 100 \\
2,2-diméthylbutane & 74,4 & 96 \\
2,3-diméthylbutane & 75,2 & 88 \\
Méthylcyclopentane & 84,1 & 99 \\
\hline LFM9 & 756,6 & 39 \\
\hline
\end{tabular}

* Quantité d'hydrocarbure par litre de milieu de culture.

** Moyenne de deux essais.

*** Considérant chaque hydrocarbure dosé dans les témoins abiotiques, les taux de recouvrement étaient de $85 \pm 3 \%$ de la quantité initialement introduite. 
TABLEAU 12

Biodégradation du mélange modèle de l'essence étêtée (GM23) par M. austroafricanum IFP 2173

Biodegradation of the topped-gasoline model mixture (GM23) by M. austroafricanum IFP 2173

\begin{tabular}{|c|c|c|}
\hline Hydrocarbures & Concentration initiale $*\left(\mathrm{mg} \cdot \mathrm{l}^{-1}\right)$ & Taux de dégradation $* *, * * *(\%)$ \\
\hline$n$-heptane & 13,7 & 100 \\
\hline$n$-octane & 15,2 & 100 \\
\hline 2-méthylhexane & 13,3 & 93 \\
\hline 3-méthylhexane & 14,0 & 92 \\
\hline 3-méthylheptane & 14,9 & 95 \\
\hline 2,4-diméthylhexane & 15,2 & 83 \\
\hline 2,5-diméthylhexane & 14,2 & 74 \\
\hline 2,2,4-triméthylpentane & 14,2 & 97 \\
\hline 2,3,4-triméthylpentane & 15,2 & 100 \\
\hline Cyclohexane & 15,3 & 57 \\
\hline Benzène & 18,1 & 13 \\
\hline Toluène & 18,9 & 93 \\
\hline Éthylbenzène & 20,2 & 100 \\
\hline$n$-propylbenzène & 19,6 & 100 \\
\hline$o$-xylène & 19,6 & 90 \\
\hline$m$-xylène & 19,1 & 92 \\
\hline p-xylène & 19,7 & 100 \\
\hline 2-éthyltoluène & 21,5 & 100 \\
\hline 3-éthyltoluène & 20,2 & 100 \\
\hline 4-éthyltoluène & 18,6 & 100 \\
\hline 1,2,3-triméthylbenzène & 19,0 & 50 \\
\hline 1,2,4-triméthylbenzène & 20,2 & 100 \\
\hline 1,3,5-triméthylbenzène & 20,2 & 53 \\
\hline GM23 & 400,1 & 86 \\
\hline
\end{tabular}

* Quantité d'hydrocarbure par litre de milieu de culture.

** Moyenne de deux essais.

*** Considérant chaque hydrocarbure dosé dans les témoins abiotiques, le taux de recouvrement était de $89 \pm 3 \%$ de la quantité initialement introduite.

\subsection{Cométabolisme de l'éthylbenzène}

La dégradation par cométabolisme de l'éthylbenzène a été confirmée par la détection d'un métabolite après croissance de la souche sur un milieu contenant l'isooctane, substrat de croissance, et l'éthylbenzène, cosubstrat potentiel. Ce métabolite a été identifié, par CPG couplée à la spectrométrie de masse, comme étant l'acétophénone.

\subsection{Biodégradation syntrophique de cycloalcanes}

La cooxydation du cyclohexane a été étudiée avec différents substrats de croissance et les taux de dégradation du substrat et cosubstrat (cyclohexane) ont été déterminés dans chaque cas (tableau 13). La cooxydation du cosubstrat en cyclohexanone est observée avec tous les hydrocarbures testés et avec l'éthanol ou l'acétate. Un autre métabolite peut être identifié par spectrométrie de masse. Il s'agit du cyclohexène. Les quantités de cyclohexanone et cyclohexène détectées indiquent que le cyclohexane est principalement transformé en cyclohexanone et que le cyclohexène est un coproduit de cette oxydation. La souche IFP 2173 étant incapable de dégrader la cyclohexanone, nous avons cherché à minéraliser complètement le cyclohexane en réalisant une culture mixte.

Une souche ayant la capacité de dégrader la cyclohexanone a été isolée (souche IFP 2149) à partir de boues de station d'épuration urbaine, puis identifiée comme appartenant à l'espèce Acinetobacter lwoffii. A. lwoffii IFP 2149 n'est capable de dégrader ni l'isooctane, ni le cyclohexane (tableau 14). Lors de la réalisation d'une culture mixte mettant en œuvre l'isooctane et le cyclohexane, le taux de dégradation du cyclohexane est similaire à celui obtenu avec $M$. austroafricanum IFP 2173 seule, mais aucune accumulation de cyclohexanone n'est observée. La production de $\mathrm{CO}_{2}$ dans le cas de la culture mixte est nettement supérieure à celle obtenue avec M. austroafricanum seule (fig. 10). L'augmentation de la production de $\mathrm{CO}_{2}$ démontre la minéralisation de la cyclohexanone par A. lwoffii IFP 2149.

La mise en œuvre d'une culture mixte a ainsi permis de dégrader et minéraliser le cyclohexane en associant cométabolisme et commensalisme. 


\section{TABLEAU 13}

Influence du substrat sur le cométabolisme du cyclohexane par M. austroafricanum IFP 2173

Substrate effect on cometabolism of cyclohexane by M. austroafricanum IFP 2173

\begin{tabular}{|c|c|c|c|c|c|c|c|}
\hline \multirow{2}{*}{ Substrats } & \multirow{2}{*}{$\begin{array}{c}\text { Période } \\
\text { d'incubation } \\
\text { (j) }\end{array}$} & \multicolumn{2}{|c|}{$\begin{array}{c}\text { Taux } \\
\text { de dégradation }(\%)\end{array}$} & \multicolumn{3}{|c|}{ Quantité finale $(\mu \mathrm{mol})$} & \multirow{2}{*}{$\begin{array}{c}\text { Taux } \\
\text { de recouvrement } * * * *\end{array}$} \\
\hline & & Substrat* & Cyclohexane*, ** & Cyclohexane & Cyclohexanone & Cyclohexène & \\
\hline Heptane & 21 & 100 & 76 & 5,8 & 15,5 & 0,8 & 0,93 \\
\hline Octane & 21 & 100 & 76 & 5,8 & 14,8 & 0,7 & 0,89 \\
\hline 2-méthylhexane & 21 & 100 & 77 & 5,6 & 16,0 & 0,9 & 0,94 \\
\hline 3-méthylheptane & 21 & 100 & 80 & 4,8 & 16,8 & 0,8 & 0,94 \\
\hline 2,4-diméthylhexane & 21 & 99 & 80 & 4,7 & 16,8 & 0,6 & 0,93 \\
\hline 2,5-diméthylhexane & 21 & 100 & 92 & 2,0 & 18,7 & 0,3 & 0,87 \\
\hline 2,2,4-triméthylpentane & 21 & 100 & 85 & 3,5 & 17,9 & 0,9 & 0,93 \\
\hline 2,3,4-triméthylpentane & 33 & 89 & 39 & 14,5 & 7,2 & 0,9 & 0,95 \\
\hline Toluène & 33 & 98 & 58 & 10,0 & 9,9 & 0,9 & 0,87 \\
\hline$m$-xylène & 33 & 98 & 31 & 16,5 & 5,7 & 0,1 & 0,93 \\
\hline$p$-xylène & 33 & 98 & 76 & 5,8 & 15,6 & 0,9 & 0,93 \\
\hline Acétate & 11 & 98 & 43 & 13,6 & 9,0 & 1,2 & 0,99 \\
\hline Éthanol & 4 & 69 & 60 & 9,5 & 10,6 & 1,3 & 0,90 \\
\hline
\end{tabular}

* Moyenne de deux essais.

** La quantité de cyclohexane dosée dans les témoins abiotiques était de 23,9 $\pm 1,3 \mu$ mol.

*** Le taux de recouvrement a été calculé comme le ratio molaire de la somme cosubstrat résiduel et coproduit et du cosubstrat dosé dans les témoins abiotiques.

TABLEAU 14

Dégradation du cyclohexane par cométabolisme et commensalisme

Degradation of cyclohexane by cometabolism and commensalism

\begin{tabular}{|c|c|c|c|c|c|}
\hline \multirow{2}{*}{ Microorganismes } & \multirow{2}{*}{ Source de carbone } & \multirow{2}{*}{$\begin{array}{l}\text { Taux de dégradation } \\
\text { du cyclohexane* } \\
(\%)\end{array}$} & \multicolumn{3}{|c|}{ Quantité finale $(\mu \mathrm{mol})$} \\
\hline & & & Cyclohexane & Cyclohexanone & Cyclohexène \\
\hline \multirow[b]{2}{*}{ A. lwoffii } & Cyclohexane & $<5^{* *}$ & $23,0 * *$ & $<0,1 * *$ & $<0,1 * *$ \\
\hline & $\begin{array}{l}\text { 2,2,4-triméthylpentane } \\
+ \text { cyclohexane }\end{array}$ & $<5^{* *}$ & $24,7 * *$ & $<0,1 * *$ & $<0,1^{* *}$ \\
\hline \multirow[b]{2}{*}{ M. austroafricanum } & Cyclohexane & $<5^{* *}$ & $23,4 * *$ & $1,2 * *$ & $<0,1 * *$ \\
\hline & $\begin{array}{l}\text { 2,2,4-triméthylpentane } \\
+ \text { cyclohexane }\end{array}$ & $62 \pm 4 * * *$ & $9,2 \pm 0,7 * * *$ & $12,4 \pm 0,8 * * *$ & $1,2 \pm 0,2 * * *$ \\
\hline \multirow{2}{*}{$\begin{array}{l}\text { M. austroafricanum } \\
+ \text { A. lwoffii }\end{array}$} & Cyclohexane & $<5^{* *}$ & $24,9 * *$ & $<0,1 * *$ & $<0,1 * *$ \\
\hline & $\begin{array}{l}\text { 2,2,4-triméthylpentane } \\
+ \text { cyclohexane }\end{array}$ & $65 \pm 5^{* * *}$ & $8,4 \pm 0,9 * * *$ & $<0,1 * * *$ & $1,2 \pm 0,1 * * *$ \\
\hline
\end{tabular}

* La quantité de cyclohexane dosée dans les fioles abiotiques était de 23,9 \pm 1,3 $\mu$ mol.

** Moyenne de deux essais.

*** Moyenne de trois essais. Les déviations standard sont indiquées. 


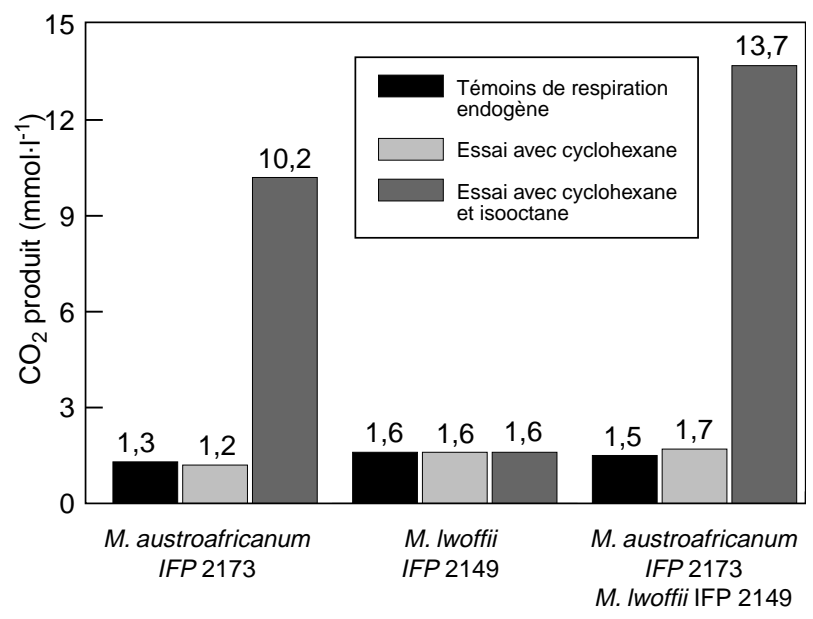

Figure 10

Production de $\mathrm{CO}_{2}$ lors de la biodégradation du cyclohexane. Production of $\mathrm{CO}_{2}$ during cyclohexane biodegradation.

\subsection{Discussion}

Afin d'étudier et pallier les déficiences des microflores natives vis-à-vis de la dégradation des triméthylpentanes, nous avons entrepris l'isolement d'un microorganisme possédant la capacité à dégrader ces composés. Pour cela, nous avons choisi l'isooctane en tant que composé modèle. En partant d'un échantillon d'eau de nappe phréatique anciennement polluée par essence, nous avons réussi à isoler une bactérie capable de croissance sur isooctane. Une telle souche n'avait pas encore été décrite. Cette souche a un spectre de dégradation d'une ampleur inhabituelle.

La propriété la plus notable de M. austroafricanum IFP 2173 est sa capacité à dégrader certains isoalcanes ayant un atome de carbone quaternaire, comme le 2,2,4-triméthylpentane et le 2,2-diméthylpentane, qui sont présentés par divers auteurs comme très résistants à la biodégradation (Thijsse et Zwilling-De Vries, 1959 ; Mc Kenna, 1972 ; Jamison et al., 1975 ; Catelani et al., 1977 ; Pirnik, 1997 ; Solano-Serena et al., 1999b). L'autre point remarquable est la capacité de la souche à dégrader les isoalcanes méthyl-antéiso-branchés, ce qui est une propriété rare (Schaeffer et al., 1979). En effet, ces composés bloquent le fonctionnement de la ß-oxydation qui intervient normalement dans le métabolisme des alcanes aliphatiques. Il est donc logique de penser que la dégradation des composés méthyl-antéiso-branchés implique chez $M$. austroafricanum IFP 2173 une étape de décarboxyméthylation (carboxylation du groupement méthyle et élimination du groupement carboxyméthyle formé), voie mise en évidence chez $P$. citronellolis lors de la dégradation du citronellol (fig. 11). Grâce à cette séquence réactionnelle, le $\mathrm{CO}_{2}$ est fixé enzymatiquement sur le groupement méthyle latéral, et le

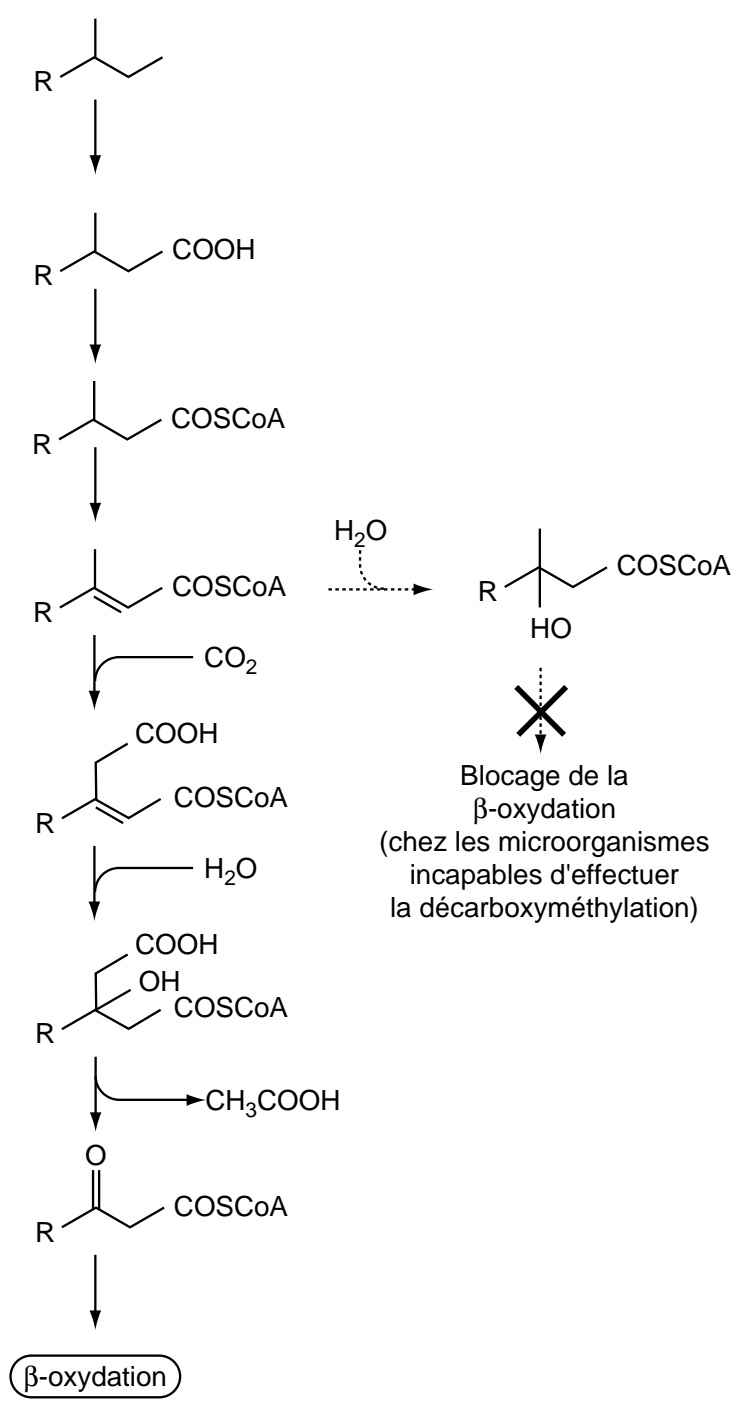

Figure 11

Voie de dégradation des 3-méthylalcanes par décarboxyméthylation (adapté de Fall et al., 1979).

Degradation pathway of 3-methylalcanes by decarboxymethylation (adapted from Fall et al., 1979).

groupement acétyle néoformé est ensuite éliminé de la molécule (Fall et al., 1979 ; Schaeffer et al., 1979). La structure d'un intermédiaire métabolique (3-méthyl 2-butanone) mis en évidence lors de la dégradation du 2,3,4-triméthylpentane est en faveur d'une telle hypothèse (résultats non présentés).

M. austroafricanum IFP 2173 présente également de larges capacités de cométabolisme, en particulier pour la dégradation des cycloalcanes. Le cyclohexane n'est habituellement pas utilisé comme substrat de croissance par les souches pures, mais des capacités similaires à celles observées ici ont été rapportées pour la souche de $M$. vaccae JOB5 qui cooxyde des cycloalcanes en utilisant le propane comme substrat de croissance (Beam et Perry, 1974a, 1974b). Le 
cométabolisme explique que la dégradation du mélange modèle d'essence GM23 par la souche IFP 2173 seule atteigne $86 \%$, ce qui est du même ordre que la dégradation mesurée avec des microflores de sol qui sont, elles, beaucoup plus complexes d'un point de vue microbiologique. Il faut noter que cette souche appartient au groupe des Mycobacterium à croissance rapide, qui jouent un rôle important dans l'environnement, en particulier grâce à leurs capacités de dégradation de xénobiotiques (Burback et Perry, 1993; Tay et al., 1998).

\section{CONCLUSION}

Ce travail a permis de préciser et d'approfondir la biodégradation de l'essence, une coupe pétrolière qui, de par son utilisation massive, constitue un polluant majeur des sols. La littérature abondante publiée sur le sujet ne concerne que certains composés, notamment les BTEX. En réalité, peu d'études ont été consacrées à la biodégradabilité de l'essence dans sa totalité. En fixant un tel objectif à notre travail, il nous a été possible d'apporter une contribution originale sur plusieurs points.

L'approche expérimentale adoptée pour cette étude sur l'essence repose sur l'évaluation des capacités dégradatrices de microflores variées et sur la détermination des structures hydrocarbonées résistantes. Elle prend en considération les possibilités de cométabolisme au sein de mélanges d'hydrocarbures et de commensalisme au sein de populations bactériennes. Les résultats ont mis en évidence la très bonne biodégradabilité de la majorité des constituants de l'essence. Compte tenu de l'importance croissante que revêt l'acceptabilité par l'environnement des produits existant sur le marché, une démarche analogue à celle développée sur l'essence mériterait d'être reprise pour évaluer de façon générale la biodégradabilité des autres produits pétroliers importants, tels que le kérosène ou le gazole. Des études sont actuellement en cours, dans notre laboratoire, sur la biodégradabilité de ces produits. Elles permettront de préciser l'étendue des risques pour l'environnement de l'utilisation massive de ces produits.

La résistance à la biodégradation des alcanes comportant un atome de carbone quaternaire met en lumière les capacités remarquables de la souche M. austroafricanum IFP 2173, sélectionnée initialement pour sa capacité à dégrader l'isooctane. Les capacités de cette souche pourraient être explorées dans les procédés d'épuration utilisant des réacteurs de type biofiltre qui permettent, dans le cas de l'essence, une bonne dégradation de nombreux hydrocarbures mais non des alcanes branchés (Ropars, communication personnelle) ou des alcanes alicycliques (Wright et al., 1997).

Au plan de la connaissance, le métabolisme de l'isooctane, et donc celui des atomes de carbone quaternaire par M. austroafricanum, est d'un grand intérêt et mériterait d'être élucidé. La croissance sur isooctane induit chez la souche
IFP 2173 la production d'un cytochrome P450 (résultats non présentés). On est par conséquent en droit de se demander comment le cytochrome P450 intervient dans les capacités de la souche à attaquer des structures récalcitrantes. La connaissance du mécanisme d'action de ce système enzymatique et de la voie de dégradation contribuerait assurément à améliorer la compréhension des phénomènes intervenant dans le processus d'atténuation naturelle de polluants récalcitrants dans l'environnement.

\section{RÉFÉRENCES}

Beam, H.W. et Perry, J.J. (1973) Co-Metabolism as a Factor in Microbial Degradation of Cycloparaffinic Hydrocarbons. Arch. Microbiol., 91, 87-90.

Beam, H.W. et Perry, J.J. (1974a) Microbial Degradation and Assimilation of $n$-Alkyl-Substituted Cycloparaffins. J. Bacteriol., 118, 394-399.

Beam, H.W. et Perry, J.J. (1974b) Microbial Degradation of Cycloparaffinic Hydrocarbons via Co-Metabolism and Commensalism. J. Gen. Microbiol., 82, 163-169.

Burback, B.L. et Perry, J.J. (1993) Biodegradation and Biotransformation of Groundwater Pollutant Mixtures by Mycobacterium vaccae. Appl. Environ. Microbiol., 59, 10251029.

Catelani, D., Colombi, A., Sorlini, C. et Treccani, V. (1977) Metabolism of Quaternary Carbon Compounds: 2,2Dimethylheptane and Terbutylbenzene. Appl. Environ. Microbiol., 34, 351-354.

Chang, M.K., Voice, T.C. et Criddle, C. (1992) Kinetics of Competitive Inhibition and Cometabolism in the Biodegradation of Benzene, Toluene, and $p$-Xylene by Two Pseudomonas Isolates. Biotechnol. Bioeng., 41, 1057-1065.

De Klerk, H. et Van der Linden, A.C. (1974) Bacterial Degradation of Cyclohexane: Participation of a Cooxidation Reaction. Ant. van Leeuw., 40, 7-15.

Di Lecce, C., Accarino, M., Bolognese, F., Galli, E. et Barbieri, P. (1997) Isolation and Metabolic Characterization of a Pseudomonas stutzeri Mutant Able to Grow on the Three Isomers of Xylene. Appl. Environ. Microbiol., 63, 3279-3281.

Durand, J.P., Béboulène, J.J. et Ducrozet, A. (1995) Detailed Characterization of Petroleum Products with Capillary GC Analyzers. Analusis, 23, 481-483.

Fall, R.R., Brown, J.L. et Schaeffer, T.L. (1979) Enzyme Recruitment Allows the Biodegradation of Recalcitrant Branched Hydrocarbons by Pseudomonas citronellolis. Appl. Environ. Microbiol., 38, 715-722.

Horowitz, A. et Atlas, M. (1977) Response of Microorganisms to an Accidental Gasoline Spillage in an Arctic Freshwater Ecosystem. Appl. Environ. Microbiol., 33, 1252-1258.

Jamison, V.W., Raymond, R.L. et Hudson, J.O. (1975) Biodegradation of High-Octane Gasoline in Groundwater. Dev. Ind. Microbiol., 16, 305-312.

Lang, E. (1996) Diversity of Bacterial Capabilities in Utilizing Alkylated Benzenes and Other Aromatic Compounds. Lett. Appl. Microbiol., 23, 257-260.

Leahy, J.G. et Olsen, R.H. (1997) Kinetics of Toluene Degradation by Toluene-Oxidizing Bacteria as a Function of Oxygen Concentration, and the Effect of Nitrate. Microbiol. Ecol., 23, 23-30. 
Lloyd-Jones, G. et Trudgill, P.W. (1989) The Degradation of Alicyclic Hydrocarbons by a Microbial Consortium. Int. Biodeter., 25, 197-206.

Logan, B.E. et Rittmann, B.E. (1998) Finding Solutions for Tough Environmental Problems. Environ. Sci. Technol., 502A$507 \mathrm{~A}$.

Mallakin, A. et Ward, O.P. (1996) Degradation of BTEX Compounds in Liquid Media and Pet Biofilters. J. Ind. Microbiol., 16, 309-318.

Mc Kenna, E.J. (1972) Microbial Metabolism of Normal and Branched Chain Alkanes, in Proc. Degradation of Synthetic Organic Molecules in the Biosphere, San Francisco, 1971, Academy of Sciences, Washington, D.C.

NF07_086 Détermination des teneurs en familles chimiques d'hydrocarbures dans les essences pour moteur automobile à partir de l'analyse détaillée, Association française de normalisation, Paris La Défense.

Nielsen, P.H., Bjerg, P.L., Nielsen, P., Smith, P. et Christensen, T.H. (1996) In Situ and Laboratory Determined First-Order Degradation Rate Constants of Specific Organic Compounds in an Aerobic Aquifer. Environ. Sci. Technol., 30, 31-37.

Nirmalakhandan, N., Brennan, R.A. et Speece, R.E. (1997) Predicting Henry's Law Constant and the Effect of Temperature on Henry's Law Constant. Water Res., 31, 1471-1481.

Paje, M.L.F., Neilan, B.A. et Couperwhite, I. (1997) A Rhodococcus Species that Thrives on Medium Saturated with Liquid Benzene. Microbiology, 143, 2975-2981.

Patel, R.N., Hou, C.T., Laskin, A.I., Felix, A. et Derelanko, P. (1983) Oxidation of Alkanes by Organisms Grown on $\mathrm{C}_{2}-\mathrm{C}_{4}$ Alkanes. J. Appl. Biochem., 5, 107-120.

Perry, J.J. (1979) Microbial Cooxidation Involving Hydrocarbons. Microbiol. Rev., 43, 59-72.

Perry, J.J. (1984) Microbial Metabolism of Cyclic Alkanes, in Petroleum Microbiology, Atlas, R.M. (ed.), Macmillan Publishers, New York, 61-97.

Pirnik, M.P. (1977) Microbial Oxidation of Methyl Branched Alkanes. CRC Crit. Rev. Microbiol., 5, 413-422.

Pirnik, M.P., Atlas, R.M. et Bartha, R. (1974) Hydrocarbon Metabolism by Brevibacterium erythrogenes: Normal and Branched Alkanes. J. Bacteriol., 119, 868-878.

Ridgway, H.F., Safarik, J., Phipps, D., Carl, P. et Clark, D. (1990) Identification and Catabolic Activity of Well-Derived Gasoline-Degrading Bacteria from a Contaminated Aquifer. Appl. Environ. Microbiol., 56, 3565-3575.

Rozkov, A., Käärd, A. et Vilu, R. (1998) Biodegradation of Dissolved Jet Fuel in Chemostat by a Mixed Bacterial Culture Isolated from Heavily Polluted Site. Biodegradation, 8, 363-369.

Schaeffer, T.L., Cantwell, S.G., Brown, J.L., Watt, D.S. et Fall, R.R. (1979) Microbial Growth on Hydrocarbons: Terminal Branching Inhibits Biodegradation. Appl. Environ. Microbiol., 38, 742-746.

Solano-Serena, F., Marchal, R., Blanchet, D. et Vandecasteele, J.P. (1998) Intrinsic Capacities of Soil Microflorae for Gasoline Degradation. Biodegradation, 9, 319-326.

Solano-Serena, F., Marchal, R., Lebeault, J.M. et Vandecasteele, J.P. (1999a) Assessment of Intrinsic Capacities of Microflorae for Gasoline Degradation, in Natural Attenuation of Chlorinated Solvents, Petroleum Hydrocarbons, and Other Organic Compounds, Alleman, B.C., Leeson, A. (eds.), Battelle Press, Colombus, Ohio, 177-182.
Solano-Serena, F., Marchal, R., Ropars, M., Lebeault, J.M. et Vandecasteele, J.P. (1999b) Biodegradation of Gasoline: Kinetics, Mass Balance and Fate of Individual Hydrocarbons. J. Appl. Microbiol., 86, 1008-1016.

Solano-Serena, F., Marchal, R., Casarégola, S., Vasnier, C., Lebeault, J.M. et Vandecasteele, J.P. (2000a) A Mycobacterium Strain with Extended Capacities for Degradation of Gasoline Hydrocarbons. Appl. Environ. Microbiol., 66, 2392-2399.

Solano-Serena, F., Marchal, R., Huet, T., Lebeault, J.M. et Vandecasteele, J.P. (2000b) Biodegradability of Volatile Hydrocarbons of Gasoline. Appl. Microbiol. Biotechnol., 54, 121125.

Solano-Serena, F., Marchal, R., Lebeault, J.M. et Vandecasteele, J.P. (2000c) Distribution in the Environment of Degradative Capacities for Gasoline Attenuation. Biodegradation, 11, 29-35.

Solano-Serena, F., Marchal, R., Lebeault, J.M. et Vandecasteele, J.P. (2000d) Selection of Microbial Populations Degrading Recalcitrant Hydrocarbons of Gasoline by Monitoring of CultureHeadspace Composition. Lett. Appl. Microbiol., 30, 19-22.

Tay, S.T.H., Hemond, H.F., Polz, M.F., Cavanaugh, C.M., Dejesus, I. et Krumholtz, L.R. (1998) Two New Mycobacterium Strains and their Role in Toluene Degradation in a Contaminated Stream. Appl. Environ. Microbiol., 64, 1715-1720.

Thijsse, G.J.E. et Van der Linden, A.C. (1961) Iso-Alkanes Oxidation by a Pseudomonas. Ant. van Leeuw., 27, 171-179.

Thijsse, G.J.E. et Van der Linden, A.C. (1963) Pathways of Hydrocarbon Dissimilation by a Pseudomonas as Revealed by Chloramphenicol. Ant. van Leeuw., 29, 89-100.

Thijsse, G.J.E. et Zwilling-De Vries, J.T. (1959) Oxidation of Straight and Branched Alkanes by Pseudomonas Strains. Ant. van Leeuw., 25, 332-336.

Trudgill, P.W. (1984) Microbial Degradation of Alicyclic Ring, in Microbial Degradation of Organic Compounds, Gibson, D.T. (ed.), Marcel Dekker, New York, 131-180.

Tsao, C.W., Song, H.G. et Bartha, R. (1998) Metabolism of Benzene, Toluene, and Xylene Hydrocarbons in Soil. Appl. Environ. Microbiol., 64, 4924-4929.

Vestal, J.B. (1984) The Metabolism of Gaseous Hydrocarbons by Microorganisms, in Petroleum Microbiology, Macmillan Publishers, Atlas, R.M. (ed.), New York, 129-152.

Watkinson, R.J. et Morgan, P. (1990) Physiology of Aliphatic Hydrocarbon-Degrading Microorganims. Biodegradation, 1, 79-92.

Woods, N.R. et Murrel, J.C. (1989) The Metabolism of Propane in Rhodococcus rhodochrous PNKb1. J. Gen. Microbiol., 135, 2335-2344.

Wright, W.F., Schroeder, E.D., Chang, D.P.Y. et Romstad, K. (1997) Performance of a Pilot-Scale Compost Biofilter Treating Gasoline. J. Environ. Eng., 123, 547-555.

Yaws, C.L. (1992) Thermodynamic and Physical Property Data, Gulf Publishing Company, Houston, Texas.

Yerushalmi, L. et Guiot, S.R. (1998) Kinetics of Biodegradation of Gasoline and its Hydrocarbon Constituents. Appl. Microbiol. Biotechnol., 49, 475-481.

Zhou, E. et Crawford, R.L. (1995) Effects of Oxygen, Nitrogen and Temperature on Gasoline Biodegradation in Soil. Biodegradation, 6, 127-140.

Manuscrit final reçu en août 2001 